\title{
Regional winners and losers in future UK energy system transitions
}

\section{Accepted Manuscript: November 2016, Energy Strategy Reviews 13-14, 11-31. doi: 10.1016/j.esr.2016.08.002}

Francis G. N. Lia, francis.li@ucl.ac.uk

Steve Pye ${ }^{a}$ s.pye@ucl.ac.uk

Neil Strachana, n.strachan@ucl.ac.uk

a UCL Energy Institute, Central House, 14 Upper Woburn Place, London, WC1H oNN,
United Kingdom

(c) 2016. This manuscript version is made available under the CC-BY-NC-ND 4.0 license http://creativecommons.org/licenses/by-nc-nd/4.0/

\begin{abstract}
This paper demonstrates the integration of institutional perspectives on energy system transitions into formal energy economic modelling. The perspectives of key UK energy system stakeholders have been used to develop three socio-technical narratives of energy system change that are quantified in a 24 -region techno-economic model of the country. Implementing these three narratives in the model environment allows their feasibility for meeting climate targets to be assessed as well as articulating their implied sub-national regional outlooks for technologies and investment. The latter elements are discussed in light of the regional socioeconomic and demographic landscape. The study highlights some of the regional political dimensions associated with future investment targeting in the UK energy system. In particular, energy policy decisions may create tensions between the four different UK government administrations as well as raising important questions about regional economic development and how an equitable energy transition can be achieved for all.
\end{abstract}

\section{Keywords}

Energy systems; energy economics; energy transitions; renewable energy; spatial modelling, decarbonisation;

\section{Highlights}

- Prominent UK transition scenarios adapted into a whole energy system model

- Integration process bridges between socio-technical theory and energy economic modelling

- Model spatial detail used to relate geographical impacts to real-world regional actors

- Tensions exposed between sub-regional optimality and national optimality

- Discussion framed around the complex regional political geography of the UK 


\subsection{Challenges for modelling the energy transition}

The use of energy economic models by governments and research institutes has come to be deeply embedded in the policy process in many countries [1]. Energy models, in the broadest sense, are employed at multiple scales. Global models are used for exploring the boundaries of human activity within biospherical limits and are central to climate policy assessment under the United Nations Framework Convention on Climate Change [2]. At the level of individual countries, models are used for understanding the potential impacts of state interventions on the economy and on the environment $[3,4]$. Models are also often applied at the sub-national scale for developing strategic energy options at a regional, urban, or district level $[5,6]$.

Models are valuable tools for thinking about the future when paired with strategic scenario planning activities [7]. Historically the principal uses for energy models included exploring future challenges to resource security and energy affordability, while today, the reduction of greenhouse gas (GHG) emissions adds a third policy imperative [8]. Understanding social, economic and political pathways that can transition different countries towards energy systems that are compatible with a climate stabilised future is a major undertaking for both scientific research and policy design.

The use of energy models faces continual challenges from within and outside the research community. Common concerns include the transparency of the model structure and data [9], the reproducibility of results [10], and whether insights from a cost optimisation approach approximate the dynamics of real-world energy transitions [11]. National scale models are also sometimes critiqued for their aggregate treatment of spatial dynamics that might drive infrastructure development costs [12]. The implied assumption of neoclassical economic rationalism regarding technology selection is also often criticised [13], as is the use of a single representative agent to capture the interaction of multiple real-world actors [14]. Concerns are sometimes raised that the apparent power of models to demonstrate solutions to complex problems leads to false confidence and the magnitude of the transition challenge being underestimated by decision makers $[15,16]$.

The modelling community has continued to respond to these issues over time through important initiatives. Efforts to improve transparency include the development of open source tools and datasets like OSeMOSYS [17] and the founding of groups such as OpenMod (http://www.openmod-initiative.org/). Concerns that models are "black boxes" whose internal workings are poorly understood have prompted development of models that facilitate exploration of parameter uncertainty [18-20], and increased the prevalence of multi-model exercises to expose uncertainties arising from model structure $[21,22]$. Other notable responses to criticism of model limitations include the development multi-regional models to explore spatial dynamics $[23,24]$, models that reflect the limited foresight of real decision makers [25], and models that incorporate detailed behavioural choice parameters [26-28].

In this paper we concentrate on increasing the policy relevance of energy systems modelling in two key ways. First, we answer some critics of energy systems approaches by demonstrating how the perspectives of societal actors and institutions can be reflected in modelling. This is achieved by adapting three widely used and popular 
narrative visions of energy system change, developed in consultation with government, business and civil society stakeholders, into a formal modelling environment. Secondly, we demonstrate how using a spatially explicit model with sub-national detail enhances the value of these existing scenarios by enabling the regional implications of energy transitions to be mapped on to the political geography of the real-world system.

\subsection{Capturing social and institutional factors in energy modelling}

The history of energy transitions shows that while innovation and markets are important factors affecting technological diffusion; governance, political power, and cultural values are also major drivers [29,30]. It is common for energy economic models to operate using abstract representations of decision-making, typically using a single agent to allocate capital on a rational, cost minimisation basis. This serves as a proxy for real-world processes where multiple stakeholders interact, often with conflicting priorities and objectives. Developing approaches that better reflect the influence of actors and institutions in technology pathway assessment is viewed as a core area for the future advancement of energy systems modelling [31,32].

The sustainability transitions community has been exploring the multi-level, actor dependent, co-evolutionary nature of technological innovation and diffusion for several decades [33,34]. Transitions have historically been explored using a number of heuristic frameworks such as the well-known multi-level perspective (MLP) [35,36]. However, these approaches are often acknowledged as being difficult to operationalise for the type of quantitative policy assessment practiced by governments in their search for pathways towards low carbon energy systems [37-39].

It has been suggested that the energy modelling and socio-technical transitions communities may be able to mutually reinforce one another through collaboration. Socio-technical insights have the potential to bring more realism to the unfolding of transitions within models, while in turn, quantitative modelling offers a path for sociotechnical perspectives to be incorporated more directly into the policy decision process as well as to have their basic accounting assumptions tested. One suggested approach for such interdisciplinary research is the recent push towards developing formal models of socio-technical transitions in energy [40-42]. Another valid approach is to use existing tools and scenarios and bridge between the different analytical disciplines [43]. This paper takes the latter approach, and explores the integration of energy system modelling with long term scenarios for socio-technical change developed by the UK's longest running energy transitions research community, the Realising Transition Pathways consortium (Section 2.1).

\subsection{Exploring spatial implications of energy transitions}

The geographical specifics of future energy decarbonisation pathways are important to explore for reasons of political feasibility, societal acceptability, and from the perspective of corporate interests. Spatial detail is crucial for understanding the core aspects of energy planning, such as regional resource availability, the geographical distribution of future demands, and the requirement to build or extend infrastructure networks. Spatiality is also key for understanding the effect of energy transitions on different 
stakeholders, especially regional actors. Multiple reviews of energy scenario studies call for work to more explicitly link insights to real-world actors as a means of increasing their relevance for policymaking $[44,45]$.

National scale models frequently constrain their spatial representation to a single region, partially due to data availability, but also due to the additional complexity and computational burden of representing inter-regional energy flows at the sub-national level. Sub-national spatial disaggregation in energy economy models remains comparatively rare in the UK, which is the context for our case study (Section 1.4). Notable exceptions include a 2-region MARKAL model for Scotland and the rest of the UK $[46,47]$, and the Energy Systems Modelling Environment (ESME) model of the UK Energy Technologies Institute (ETI) [48], which features in this paper (Section 2.4). Most UK energy decarbonisation studies to date have tended to focus on delivering insights into future energy transitions at the national aggregate level, with the regional outlook for new technologies and infrastructures, and the implications for key stakeholders such as sub-national governments and local communities remaining underexplored.

\section{$1.4 \quad$ UK policy context}

While we consider here the case study of the UK, many of the challenges associated with long term energy planning in an era of state decentralisation and increased regionalism apply across different national contexts with diverse energy, environmental, and economic objectives. Political devolution has been called a global trend [49], and continues to be a driving force in many countries which were previously characterised by highly centralised forms of governance, such as Japan [50], Kenya [51], India, Nepal [52], Mexico, and Brazil [53]. Energy transitions themselves are a global issue, with 175 states now signatories to the Paris Agreement on GHG emissions reduction [54], and 164 countries working to achieve national renewable energy targets [55].

The UK is a unitary nation state with four constituent member countries. Three of these countries, Scotland, Wales and Northern Ireland, have semi-autonomous governments with varying levels of legislative and revenue raising power, while the central UK Government in London also acts as the de facto English government. The devolved administrations have significantly increased their autonomy from the central UK Government since their creation in 1999. An increased desire for self-determination and differences in ideological and popular pressures in Scotland have led to significant policy divergence from England [56], a trend which seems only poised to accelerate in future [57]. The Scottish independence referendum of 2014 came close to breaking up the UK as a political entity, and arguably marked the start of a "newly emerging age of disunification" [58].

At the time of writing, the UK is currently experiencing a period of "constitutional flux" where the political relationships between different member countries are being renegotiated [57]. As well as sub-national tensions between the devolved administrations and the central UK government, tensions also exist between the many regions that lie within England, with the future of regional governance at this scale unclear [59]. Despite having no explicit political representation except at the UK level, English regions remain an important element of English civil and political society, with 
regional identities being particularly strong in areas such as London, the North East, and Cornwall in the South West [6o].

The "untidy" political geography of the country [59] has interesting implications for energy policy and any transition towards a shared low carbon future. The UK as a whole is committed to achieving an $80 \%$ reduction in $\mathrm{CO}_{2}$ emissions based on 1990 levels under the 2008 Climate Change Act [61], while the Scottish administration has also signed separate Scottish targets into law [62]. There remain many unresolved policy questions at the sub-national scale. How will targets set for individual nations contribute to a transition at the UK level? Which UK regions should be allocated more centrally administered funds for large-scale capital investments in infrastructure, and which territories should contribute more tax revenue to energy projects? Which local communities should be saddled with potential negative consequences such as habitat change, environmental damage, or potentially unpopular technologies such as nuclear power stations? Should the energy transition be viewed as a potential vehicle for addressing regional disparities in wealth and employment?

National-scale energy models have played a strong role in the process of setting the level of ambition for the UK contribution towards global climate mitigation efforts [63]. Multiple model analyses have triangulated the main trends required to bring about the UK energy transition along a cost minimised pathway. These include a major shift to low carbon electricity generation, the widespread electrification of heat and transport, and a reduced role for fossil fuel vehicles and unabated natural gas [64-67].

While several spatially detailed UK models have been used for exploring energy transitions, these have tended to focus on technological sub-systems such as electricity [68-73], hydrogen [74-77], and bioenergy $[78,79]$. These models have lacked a whole energy system perspective and have often not fully endogenised the effects of transitions in energy infrastructure on other sectors such as building heating and transport. Energy system optimisation models (ESOMs) that can determine cost optimal pathways for the electricity system in the context of a wider national decarbonisation strategy involving all economic sectors, are more suited to this task. Partial attempts to incorporate sub-national detail into UK whole energy system analysis have been carried out in the past. These relied on linking ESOMs with a GIS-based frameworks [80] or multi-regional infrastructure planning models [81].

\subsection{Aims and objectives}

This paper adapts three prominent and widely-used scenarios of socio-technical change in the UK energy system into a spatially explicit energy system model. Past analytical work has mainly concentrated on the technical feasibility of these scenarios within the power sector, leaving cross-sector interactions and questions of wider resource use underexplored. The process of integrating these scenarios into a formal spatial model of the whole energy system achieves multiple objectives:

i. It serves a diagnostic purpose by expanding the system boundary considered in the scenarios and testing the viability of their narratives at the system level. 
ii. It enhances the policy relevance of the scenarios by shedding light on their potential geographical implications for various sub-national regions and actors.

iii. It advances policy discourse in the UK by highlighting the potential for different approaches to the energy transition to produce strong regional disparities. This in turn, offers a path to understanding whether an unequal distribution of costs and benefits between regions is socially and politically acceptable or not, and whether there are opportunities for inter-regional cooperation.

iv. It advances the state of the art in interdisciplinary research by demonstrating integration between the analytical disciplines of socio-technical transitions theory and energy systems modelling.

Section 1.0 has already covered the rationale for undertaking this work and described the policy context for the case study. Section 2.0 describes the project background within which this work was undertaken, gives an overview of the scenarios used, explores the key features of the energy model employed, and explains the integration process. Section 3.0 presents the spatial results and discusses the interesting features found in each transition pathway. Section 4.0 reflects on what the modelling exercise reveals about the feasibility of the scenarios, presents a cross-comparison of regional impacts, and evaluates the transitions from the perspective of affordability, equity and public attitudes, while also touching on the implications for policy and for future research. Section 5.0 summarises the main conclusions of the study and makes the case for modellers to participate where possible in interdisciplinary research as a means of enhancing the policy relevance of modelling, despite the challenges it brings. Finally, the Online Supplementary Information included with this paper contains an expanded description of the scenario storylines and a sector-by-sector breakdown of model calibration inputs. These are not required to understand the paper, but interested readers may find them useful.

\subsection{Modelling and analysis approach}

\subsection{Realising Transition Pathways (RTP)}

The Transition Pathways (TP) project and its successor, Realising Transition Pathways (RTP), are interdisciplinary studies of the UK's transition towards a low-carbon future that were carried out principally between 2008-2016 by a consortium of the UK's leading research universities $[82,83]$. The Realising Transition Pathways narratives have captured the attention of key decision makers over the last 8 years and continue to remain influential in UK policy circles. RTP remains a key reference point for UK energy policy research as one of the only long term decarbonisation pathway studies to explicitly address actor and institutional perspectives in its scenario framework and to explore them simultaneously from economic, engineering, and behavioural research standpoints. The project is notable for its strong emphasis on:

i. Exploring the co-evolutionary nature of technological, behavioural and institutional responses to achieving energy system change. 
ii. Incorporating stakeholder perspectives on how transitions can be shaped by different government, market and social actors into quantitative assessment.

iii. Understanding the process of bridging between research disciplines and critically reflecting on the process [84].

The RTP approach can be contrasted against many similar studies which have often not addressed actor perspectives or achieved stakeholder engagement to the extent seen in this project, and typically differentiate between scenarios using dimensions such as climate policy ambition (e.g. BAU, low ambition, high ambition pathways), technological change (e.g. renewable energy-led, nuclear energy-led), or overall demand (e.g. low, medium, high). A serious attempt to consider the social dimension, in particular, has historically often been absent from much model-based energy research [85].

\section{The RTP scenarios in the policy engagement process}

This paper can be viewed as the latest step in multi-stage process, with each step building on previous work. The process is aimed at improving the relevance of the RTP pathways for policy. As will be explained in more detail below, the existing pathway narratives have been well defined from a power systems perspective, but their crosssector implications, their emission pathways, their implied resource requirements and their spatial dimensions have been largely unexplored to date. A graphical illustration is given below in Figure 1. To summarise:

\section{(A) Dialogue with stakeholders}

Researchers began the project by entering into consultation with key stakeholders in the UK energy system [83]. Government bodies involved included the Department of Energy and Climate Change (DECC), the UK energy sector regulator (Ofgem), and the Committee on Climate Change (CCC), a statutory regulatory body set up to monitor and advise on UK Government progress towards national climate targets. Market participants included representatives from the so-called "Big Six" UK energy companies [86], and the transmission system operator, National Grid. Also consulted were independent third sector organisations such as the WWF and the Centre for Alternative Technology (CAT) that represent important civil society actors in the UK energy policy field.

\section{(B) Transition pathway narratives}

Out of the dialogue process emerged three principal "visions" [87] or pathways for the future socio-technical transition which served as vehicles for integrating insights from different research disciplines such as engineering, economics, psychology, anthropology and history. This has allowed the pathways to be explored not only in terms of their technical dimensions, which is common in energy policy assessment studies, but also in terms of the institutional governance [88], business models [89] and policy interventions [90] that might be needed to realise the transitions.

The three pathway narratives all describe futures with a similar normative goal, the decarbonisation of the energy system, but achieve this transition through different means. These scenarios have been found to be compelling by UK 
policymakers due to their focus on not only the technical evolution of the electricity supply system but also because they explicitly elaborate on the behaviour and motivations of key stakeholders. The pathways each represent a stylized worldview of how energy system change might unfold, and are characterised as being either market-, government- or civil society-led. Researchers engaged in a multi-year process of dialogue with various stakeholders which has contributed to iteratively refining the narratives through time (X). The pathways, which are the subject of multiple research publications, have their key features summarised below in Section 2.3.

(C) Technical elaboration process (electricity system)

An important part of the process of policy engagement and critical reflection on the pathways involves exploring their technical feasibility. This has been investigated to date using detailed engineering simulation models of the electricity system $[91,92]$, ultimately resulting in some elements of the pathway narratives being revised in light of the findings $(Y)$.

\section{(D) Techno-economic assessment (whole energy system)}

This is where the work presented in this paper falls into the overall policy engagement process. While the technical feasibility of the scenarios within the power sector has been investigated in detail by past publications under (C), there remain important unknowns regarding cross-sector interactions, resource use, and climate target compliance. Past model-based studies using the pathways have not endogenised important considerations such as the costs of any transition or the availability of key resources, such as bioenergy.

One assessment found that the Market Rules narrative may fail to hit UK 2050 $\mathrm{CO}_{2}$ targets and suggested that additional mitigation measures not captured in their modelling such as "hydrogen production with CCS for use in transport" might be needed [92]. A cross-examination of the Central Co-ordination narrative with multiple models has also found "inconsistencies" in the narrative and concluded that the storyline had a "fragile nature", ultimately proposing that the scenarios should continue to be iteratively developed further in future to close the credibility gap [22]. Implementation in a whole energy system model was recommended as the logical next step [93]. This paper describes such a process. In turn, the insights arising from this paper will be used to iterate the narrative development process in future (Z). 
Figure 1 - Enhancing policy engagement process using Realising Transition Pathways research
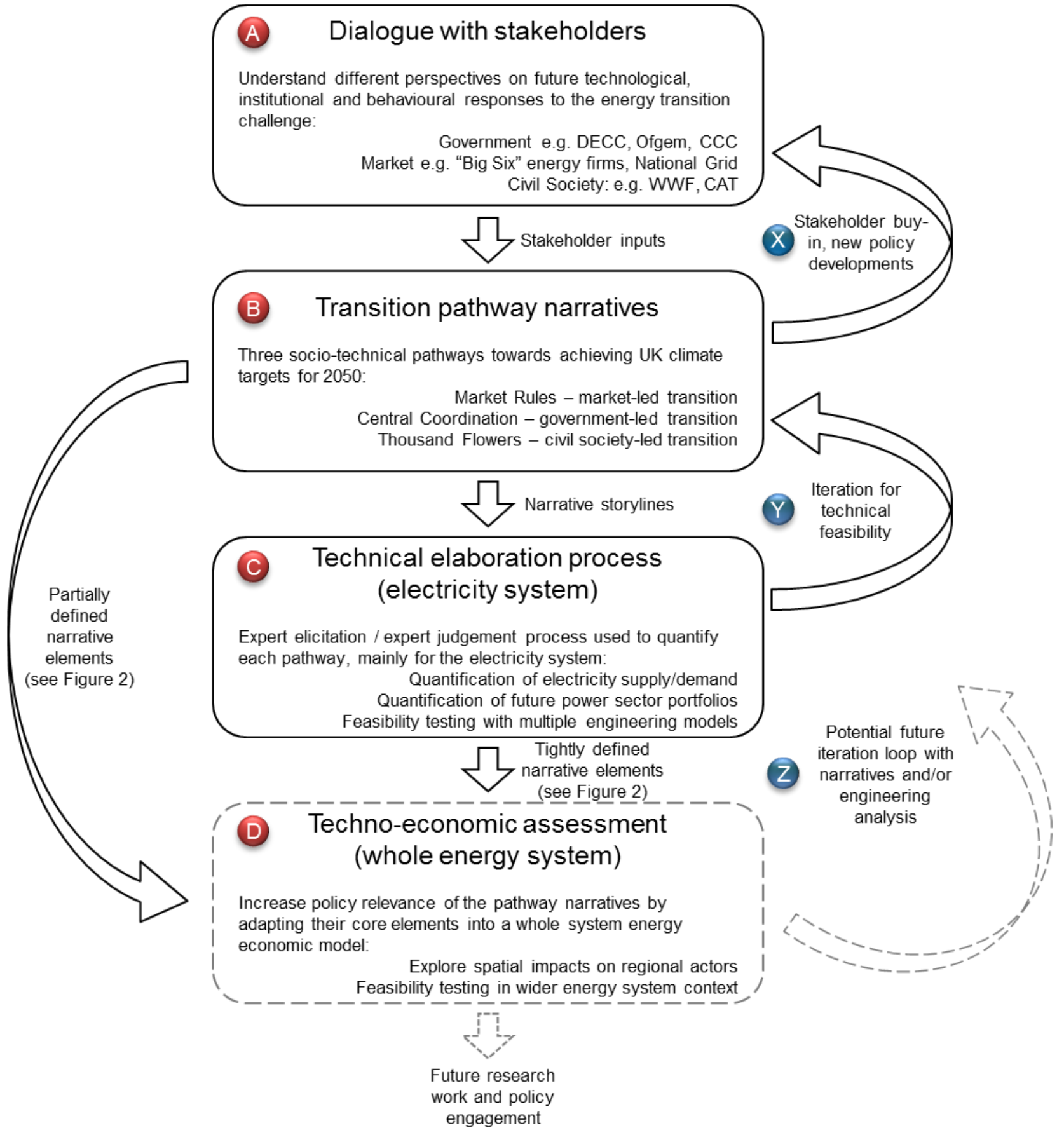
institutional and behavioural responses to the energy transition challenge

Government e.g. DECC, Ofgem, CCC Market e.g. "Big Six" energy firms, National Grid Civil Society: e.g. WWF, CAT

\subsection{Pathway summary}

A brief summary of the narrative elements of the Realising Transition Pathways scenarios is described below in Table 1. An expanded description of the storylines and the envisaged roles for government, businesses and consumers can be found in the Online Supplementary Information. In the first pathway, Market Rules, private companies drive the transition under a legislative framework that incentivises investment in low carbon generation through the introduction of a high carbon price. Energy efficiency measures meet with only limited success at the same time as widespread electrification of heating, transport and industrial demand occurs, leading to large increases in overall electricity consumption. In the second pathway, Central Co-ordination, the government takes an interventionist role in bringing about system change through issuing direct 
contracts for generation capacity. Electrification of end-use sectors is widespread, but moderate success in energy efficiency limits overall increases in demand. The third narrative, Thousand Flowers, describes a low carbon transition where civil society acts as a principal agent of change, and is characterised by significant deployment of community energy schemes and the widespread penetration of distributed microgeneration. This is in direct contrast to Market Rules and Central Co-ordination, which are dominated by the deployment of large-scale centralised low-carbon generators. Energy efficiency measures and behavioural change, combined with less electrification of building heating, strongly limits increases in electricity demand relative to the other scenarios.

Table 1 - Summary of core transition narratives

\begin{tabular}{|c|c|c|c|c|}
\hline $\begin{array}{l}\text { Transition } \\
\text { Narrative }\end{array}$ & $\begin{array}{c}\text { Principal Agent } \\
\text { of Change }\end{array}$ & Key Narrative Elements & Demand & Supply \\
\hline Market Rules & $\begin{array}{l}\text { Corporate } \\
\text { utilities: The "Big } \\
\text { Six" UK energy } \\
\text { companies and } \\
\text { their successors }\end{array}$ & $\begin{array}{l}\text { Government puts in place an electricity } \\
\text { market framework with high carbon } \\
\text { prices and supports early and successful } \\
\text { deployment of Carbon Capture and } \\
\text { Storage (CCS) technology as well as } \\
\text { offshore wind. } \\
\text { Existing market players retrench } \\
\text { decarbonisation efforts around large } \\
\text { scale technologies, with distributed } \\
\text { generation failing to emerge. }\end{array}$ & $\begin{array}{l}\text { Large scale } \\
\text { electrification of heat, } \\
\text { transport, and } \\
\text { industrial processes. } \\
\text { Limited success of } \\
\text { energy efficiency } \\
\text { programmes leads to } \\
\text { large increase in } \\
\text { electricity demand by } \\
2050(+50 \%) \text {. }\end{array}$ & $\begin{array}{l}\text { Key electricity } \\
\text { technologies: Fossil } \\
\text { Thermal CCS } \\
\text { Nuclear, } \\
\text { Offshore Wind, }\end{array}$ \\
\hline $\begin{array}{l}\text { Central } \\
\text { Co-ordination }\end{array}$ & $\begin{array}{l}\text { The nation state: } \\
\text { a Strategic } \\
\text { Energy Agency } \\
\text { set up by the } \\
\text { government to } \\
\text { direct the energy } \\
\text { transition }\end{array}$ & $\begin{array}{l}\text { Government establishes a Strategic } \\
\text { Energy Agency that issues central } \\
\text { contracts for procurement of generation } \\
\text { plant to bidders. } \\
\text { To minimise disruption to the } \\
\text { established institutional framework, } \\
\text { government concentrates on delivery of } \\
\text { large-scale low carbon generation, } \\
\text { especially nuclear power, and } \\
\text { technologies where the UK may be able } \\
\text { to develop a viable export market, such } \\
\text { as offshore wind }\end{array}$ & $\begin{array}{l}\text { Large scale } \\
\text { electrification of heat, } \\
\text { transport, and } \\
\text { industrial processes. } \\
\text { Increases in electricity } \\
\text { demand in the period } \\
\text { to } 2050 \text { are limited } \\
(\mathbf{+ 2 0 \% )} \text { through } \\
\text { successful energy } \\
\text { efficiency } \\
\text { programmes. }\end{array}$ & $\begin{array}{l}\text { Key electricity } \\
\text { technologies: } \\
\text { Nuclear, } \\
\text { Onshore Wind, } \\
\text { Fossil Thermal CCS } \\
\text { Offshore Wind } \\
\text { Marine Power }\end{array}$ \\
\hline $\begin{array}{l}\text { Thousand } \\
\text { Flowers }\end{array}$ & $\begin{array}{l}\text { Civil society: a } \\
\text { bottom-up } \\
\text { transition led by } \\
\text { community } \\
\text { energy groups }\end{array}$ & $\begin{array}{l}\text { Widespread growth in community-scale } \\
\text { energy deployment and consumer } \\
\text { involvement in energy supply, } \\
\text { facilitated by a sympathetic regulatory } \\
\text { and governance regime. } \\
\text { Large-scale deployment of distributed } \\
\text { micro-generation occurs and electricity } \\
\text { from community energy schemes } \\
\text { expands to meet 50\% of supply. } \\
\text { Large-scale utilities diversify their } \\
\text { business models to enter the Energy } \\
\text { Service Company (ESCO) market or } \\
\text { accept the loss of market share and } \\
\text { concentrate on providing grid balancing } \\
\text { services. }\end{array}$ & $\begin{array}{l}\text { Large scale } \\
\text { electrification of } \\
\text { transport and } \\
\text { industrial processes, } \\
\text { but much less heat is } \\
\text { electrified owing to } \\
\text { the popularity of } \\
\text { bioenergy CHP. } \\
\text { Energy efficiency } \\
\text { programmes } \\
\text { combined with } \\
\text { behavioural change } \\
\text { over time limits the } \\
\text { increase in electricity } \\
\text { demand to } 10 \% \text { by } \\
2050 \text {. }\end{array}$ & $\begin{array}{l}\text { Key electricity } \\
\text { technologies: } \\
\text { Bioenergy fuelled } \\
\text { combined heat and } \\
\text { power (CHP), } \\
\text { Solar PV, } \\
\text { Onshore Wind, } \\
\text { Fossil Thermal CCS }\end{array}$ \\
\hline
\end{tabular}


Energy system optimisation models (ESOMs) that explore technology portfolio choice using linear programing techniques are particularly well suited to exploring complex trade-offs between resource availability, cost, and environmental impacts. The Energy Systems Modelling Environment (ESME) is a bottom-up techno-economic model developed by the UK Energy Technologies Institute (ETI) [48]. Like other ESOMs (e.g. MARKAL [94], TIMES [26], MESSAGE [95], OSeMOSYS [17]) the model employs an inter-temporal cost minimisation algorithm to balance energy supply and demand across all sectors of the economy through the deployment of new technologies under operational and resource constraints. ESME has been used for decarbonisation pathway analysis by not only the ETI and their member organisations, but also by the Committee on Climate Change [96], UK academia [97,98], and the government's own Department of Energy and Climate Change [99]. ESME can be distinguished from a similar models by its spatial disaggregation into 24 regions ( 12 on land, 9 offshore, and 3 offshore carbon sequestration locations), which will be the focus of the analysis presented here.

ESME covers the buildings, transport, and industry sectors as end-use demands. From a supply perspective, ESME covers downstream energy production from primary resources i.e. they appear in the model as fuel products or feedstocks that have already been extracted and refined into usable forms rather than as pure raw materials. ESME is a technologically rich model, with detailed representations of existing and future options for energy conversion, storage, transmission and distribution infrastructure, buildings, industry and transport. As well as covering the electricity system, ESME is detailed in its representation of heat networks, hydrogen, carbon capture, and bioenergy conversion chains. The model is also not limited to building new capital stock in pursuit of its objectives but also has options to retrofit existing assets like buildings and power stations, and to reinforce existing networks. ESME aims to represent the total costs of energy system transformation, which are projected forward in 5-year intervals from a 2010 baseline. The ESME objective function is constrained to meet carbon and resource limits defined at each time step, and is also required to balance energy demand and supply in all diurnal and seasonal time periods.

While not possessing the same level of engineering detail in each sector as other models used on the Realising Transition Pathways project to date, the ESME model benefits from breadth, providing a simultaneous assessment of technical feasibility, economic costs, and environmental target compliance across all end-use sectors as well as a detailed description of energy supply vectors that have not been explored to date in depth, such as those for district heating, bioenergy and hydrogen.

\subsection{Adapting pathways into ESME}

Typical practice for using ESOMs involves defining a model database with cost and performance information on different technologies, and a reference energy system that describes process interactions, e.g. what types of resource can be converted along which paths to meet end-user demands. The models are then often given many degrees of freedom regarding technology selection to meet environmental and resource use targets and used to generate solutions that minimise economic costs. 
Representing the cost optimal pathway for transitions is a useful exercise, but this represents only one set of possible outcomes for the energy system. Real-world processes where multiple actors negotiate, reach compromises or compete strategically are abstracted into a single rational planning agent. Results achieved under such a modelling paradigm effectively assume that real-world actors are tightly coordinated, and that investment decisions are made on the basis of maximising net social welfare. This is of course, one set of valid set assumptions to make, but equally plausible outcomes are found in work exploring so-called "second best" [100] futures that take into account political and social barriers that might make achieving the mathematically optimal outcome impossible $[27,101,102]$. This is the category into which this study falls. We seek to reflect societal and institutional factors in our work and in particular, the perspectives of our energy system stakeholders (see Section 2.2).

In this paper, we demonstrate an approach for integrating existing scenario narratives into energy system modelling by heavily constraining technology selection in some parts of the model while offering various degrees of freedom to other elements (Section 2.6). The constraining of power sector generation along specific pathways, in particular, is carried out intentionally to reflect the views of UK policymakers on technology deployment levels that may arise under our existing socio-technical scenarios (Section 2.3).

Reflecting these power sector scenarios in a formal whole system model enables their feasibility for meeting UK climate targets (which are assessed at the system level) to be tested explicitly, and also directly enhances the policy relevance of energy system models in the UK more generally by demonstrating their ability to build-on and expand the horizons of existing widely recognised research efforts. The integration process can be thought of as one example of a "bridging" exercise between the analytical disciplines of socio-technical transitions theory and energy system modelling [43]. The process of expanding the storyline narratives into a formal model environment to allow further interrogation and testing can be characterised as one of using the model as a "prosthesis for the imagination" in the tradition of long term policy analysis [103].

Therefore, rather than exploring a least cost pathway that ignores stakeholder views on changing socio-technical preferences, institutional developments, and non-cost barriers to technology deployment, the purpose of using a model in this paper is to:

i. Explicitly reflect the stakeholder perspectives on future developments in the UK energy system that have emerged from a multi-year dialogue and engagement process, allowing the insights from this paper to align with and complement other research on business models, policy design and institutional governance that has emerged from the Realising Transition Pathways project (Section 2.2)

ii. Use the rich system characterisation, technological detail and cost optimisation framework of the ESME model to elaborate on loosely defined or undefined narrative elements, especially the spatial deployment of technologies (which impacts various real-world actors), and explore cross-sector interactions between the power sector (as imagined in the original storylines) and other parts of the energy system (more detail is given below in Section 2.6). 
iii. Explore the viability, or indeed the fragility (see discussion on past inconsistencies in Section 2.2) of the existing scenario narratives when the system boundary is expanded from the power sector to include the wider energy system (some insights in this regard are discussed in Section 4.1).

\section{$2.6 \quad$ Modelling process}

The key elements of the Market Rules, Central Co-ordination, and Thousand Flowers pathways were implemented in ESME v3.4, following a "Storyline and Simulation" approach [104]. In the interest of brevity, a sector-by-sector breakdown of key model inputs under each scenario are provided in the Online Supplementary Information for this paper. All scenarios were constrained to meet long term GHG reduction targets along a linear decarbonisation trajectory from 2010 to 2050 which approximates the process of setting 5-year carbon budgets that is enshrined in UK climate policy legislation [61]. Changes to fuel prices through time were aligned with central government projections from DECC [105].

Figure 2 provides a graphical summary of the principles applied in adapting the narrative storylines into the model environment:

1. The Tightly Defined Narrative Elements, such as the national power sector generation portfolios found in each pathway and aggregate changes to electricity demand over time are replicated in the model through the use of build rate and capacity constraints, effectively matching the parameters used in past work under the technical elaboration process (Section 2.2)

2. The pathways feature several Partially Defined Narrative Elements, such as aggregate changes in industrial demand, which have their broad characteristics described in the storyline but not the specific technological details. These are implemented in the model by constraining the overall demand trajectories (e.g. industrial demand) to match those in the narratives while using the least cost functionality of the ESME model to see which specific technologies might be selected to enable these transitions. This allows some of the detail of energy transitions outside of the power sector to be explored while maintaining the integrity of the scenario narratives themselves.

3. Finally, there are Largely Undefined Narrative Elements in the existing storylines. These include technological transitions in non-road transport sectors such as aviation, the spatial deployment of technologies, primary resource use, and whether the scenarios actually comply with national emissions targets. Here, the model data, process structure, and cost optimisation framework for investment allocation decisions is used as a means of exploring details in the pathways that were never formally quantified by the stakeholder groups involved in the narrative development process, and as a means of understanding the technical feasibility of the existing storylines. For example, in the case of power generation technologies, we rely on the intertemporal cost minimisation formulation of the model to regionally disaggregate the overall power sector portfolios that are established in the narratives at the national level. We also rely on the GHG accounting feature of the model to understand whether the 
modelled scenarios achieve the climate policy targets or not i.e. whether the model solves with the imposed GHG constraints. The spatial trade-off between locating energy supply within a given region and importing or exporting from other regions is determined on a cost basis as a function of:
a. Existing transmission capacity
b. Constraints on siting power plant in a given region
c. Regional resource availability
d. Existing generation capacity

Figure 2 - Adaptation of transition pathway narratives to model environment and expansion of system boundaries

(1) Tightly Defined Narrative Elements

Definition: elements with detailed descriptions in the pathway narratives, already explored with extensive technical elaboration process

Translation into model: align parameters with results of past studies as closely as possible, using build rate and capacity constraints to effectively simulate these elements in a defined fashion

2 Partially Defined Narrative Elements

Definition: narrative details which have been only described in an incomplete fashion to date, with typically the broad outline sketched out, but few specifics

Translation into model: constrain the aggregate trajectory (e.g. total demands) to match narratives but allow the model to select technologies on a cost basis

\section{Expansion of System Boundaries}

3 Largely Undefined Narrative Elements

Definition: aspects of the existing pathway storylines that have not been explored to date in detail or for which little to no description is available

Translation into model: allow the model to select technologies on a cost basis, use the model default parameters as boundary conditions 
The modelling process outlined in Section 2.6 revealed that for all 3 narrative pathways the ESME model found it impossible to achieve national emissions reduction targets by 2050 without pursuing a bioenergy sequestration strategy. The level of bioenergy imports was then progressively raised for all three scenarios until the model found working solutions. The implications of this finding for the feasibility of the pathway narratives are discussed further in Section 4.1. Given the stated focus of this paper on spatial issues, we focus the remainder of our results analysis on the geographical distribution of power sector investments and the implications for different sub-national regions.

\subsection{Market Rules}

Market Rules has the highest electricity demand of all three scenarios, given the limited progress made in the deployment of energy efficiency measures under the storyline (Section 2.3), and also has the highest installed capacity. Market Rules sees large-scale deployment of fossil thermal generation with carbon capture and storage (CCS), offshore wind energy and marine power (Figure 3). The scenario also involves a limited amount of unabated fossil thermal capacity. Nuclear power also expands from contemporary levels, although not to the extent envisaged under the alternative Central Co-ordination case. Land-based regions on the English East coast receive strong investments in fossil thermal CCS plant. The British North Sea, off the East coast of England, is an area of high potential for carbon sequestration $[106,107]$, with this assumption reflected in the ESME model. The spatial distribution of CCS plant is the result of the model seeking to minimise investments in transmission capacity both for electricity and captured $\mathrm{CO}_{2}$. The East coast regions of England emerge as attractive locations for CCS plant not only because of their proximity to offshore carbon storage reservoirs, but also because London, the South East, and the East of England are major demand centres. The system also places some CCS plant in the West Midlands region, which is also a key demand centre and a strategic central position on the transmission network.

Around $30 \%$ of total electricity generation capacity in Market Rules is offshore wind, marine, or tidal power. Due to the particular geographical distribution of resource potential assumed by the ESME model, this results in Scotland seeing strong investments in wind and tidal energy. As a consequence, Market Rules requires around $30 \%$ greater investment in inter-regional electricity transmission compared to Central Co-ordination and Thousand Flowers, which is associated with strengthening existing infrastructure to supply power to the South of the UK. While investment broadly follows demand centres, as might be expected, two of the largest investment regions that stand out from this analysis (accounting for onshore and offshore assets) are Scotland and the East of England (Figure 4). 
Figure 3 - Market Rules, geographical distribution of electricity generation capacity by type in 2050

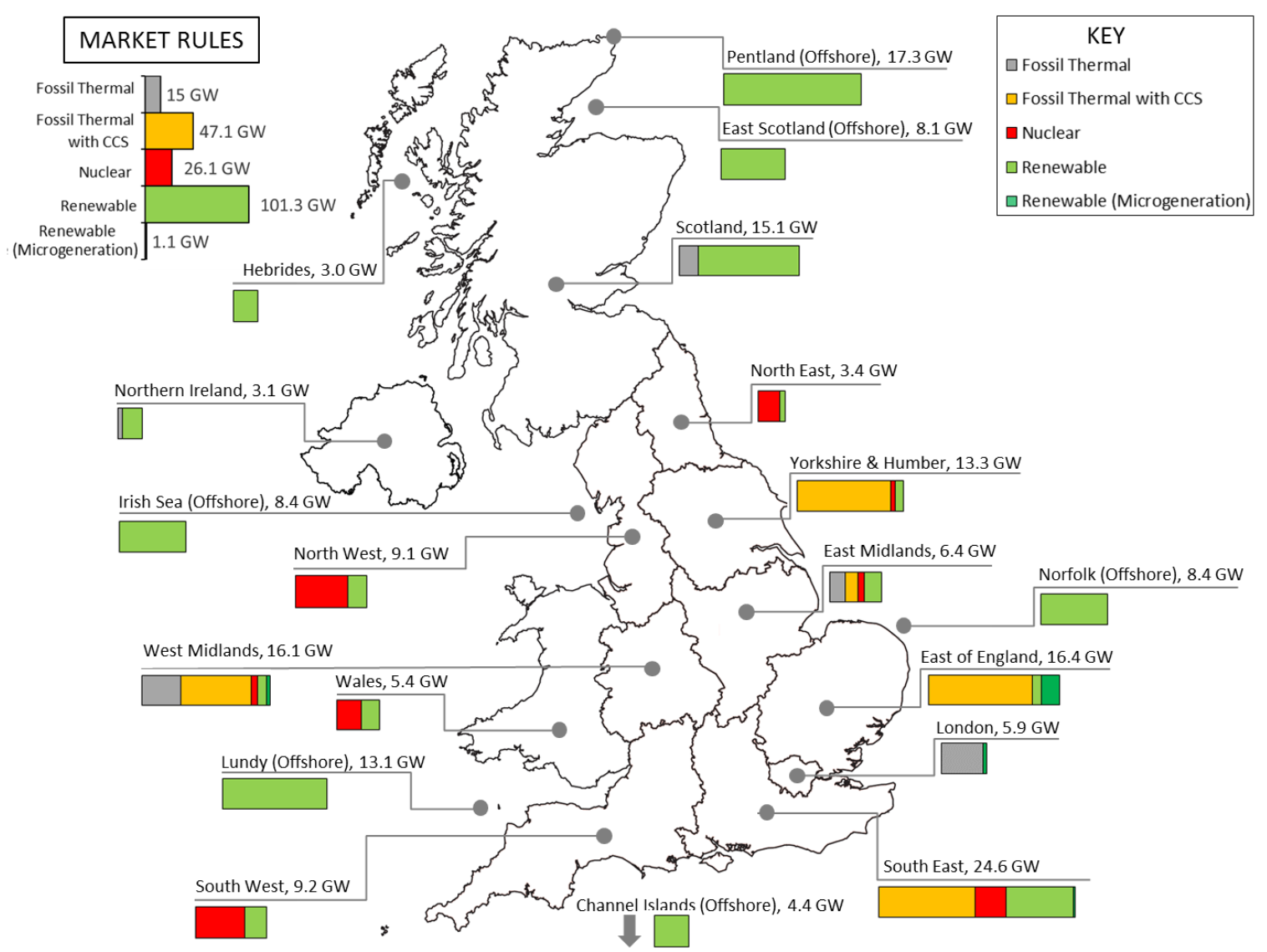

Figure 4 - Market Rules, geographical distribution of cumulative electricity system investments to 2050

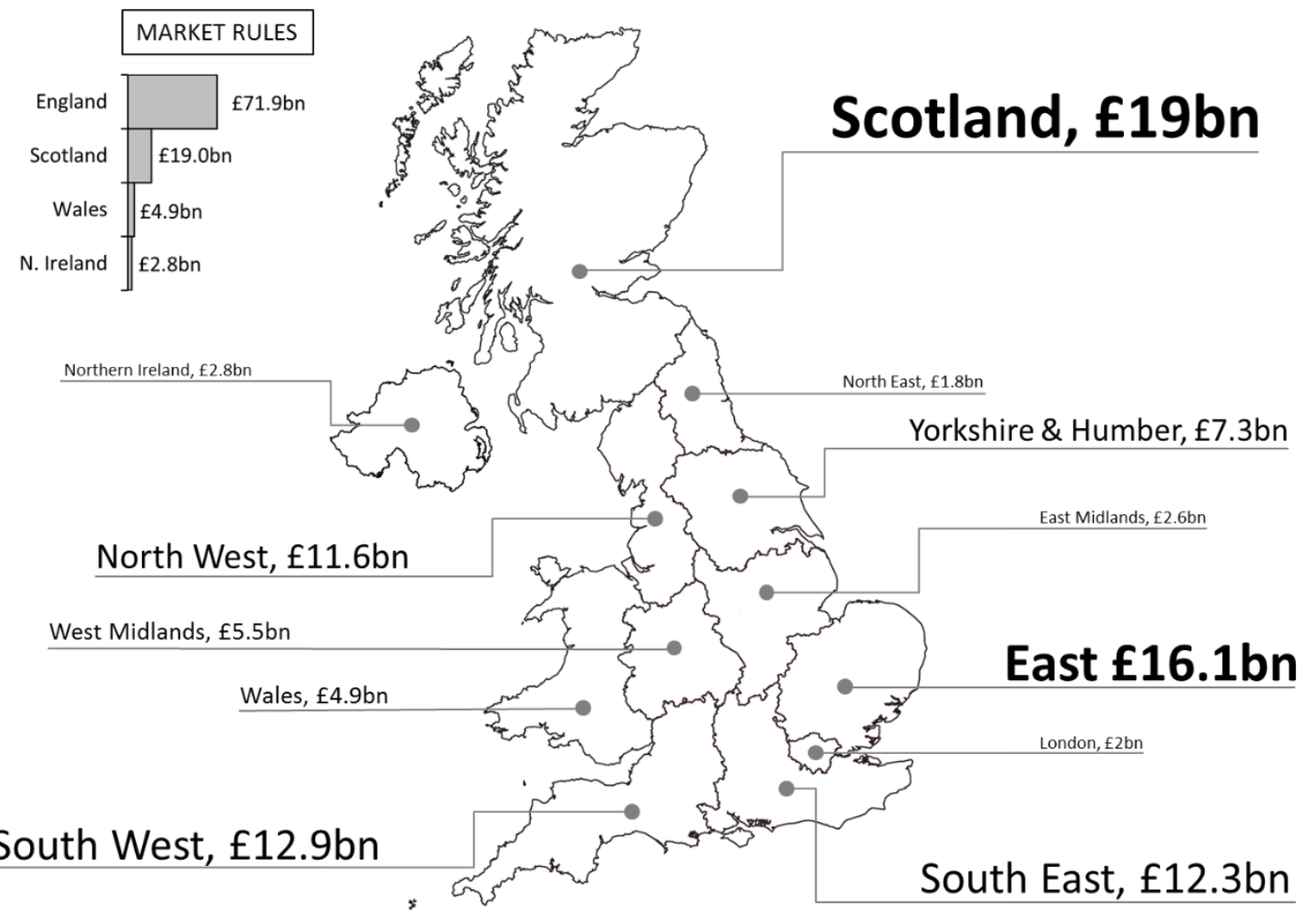


The Central Co-ordination scenario has changes to electricity demand over time that result in overall consumption being lower than Market Rules but higher than Thousand Flowers. The storyline features some progress in deployment of energy efficiency measures under the narrative (Section 2.3), but also strong electrification of heat and transport. Central Co-ordination actually has the lowest installed capacity of all three scenarios, owing to its strong reliance on baseload nuclear and fossil CCS plant and the assumed intermittency of renewables under Thousand Flowers (Section 3.3).

Central Co-ordination is characterised by a large expansion of nuclear power in England and Wales. The regions which emerge from the modelling with the largest concentrations of new nuclear deployment are the South East, the South West, the North West and the North East (Figure 5). Fossil CCS and large-scale renewable energy are distributed in a similar fashion to Market Rules, although the overall scale of their deployment is lower, particularly for marine renewables. This is because under Central Co-ordination, more of the future demand for energy, which is dominated by England, is met by nuclear power physically located in England, Wales or in offshore regions close to England. This lessens the requirement for transmission capacity investments on long distance parts of the network, such as improving the connectivity between the South of England and Scotland. When compared to Market Rules, the distribution of cumulative investment required to 2050 shifts away from Scotland and towards English regions (Figure 6). 
Figure 5 - Central Co-ordination, geographical distribution of electricity generation capacity by type in 2050

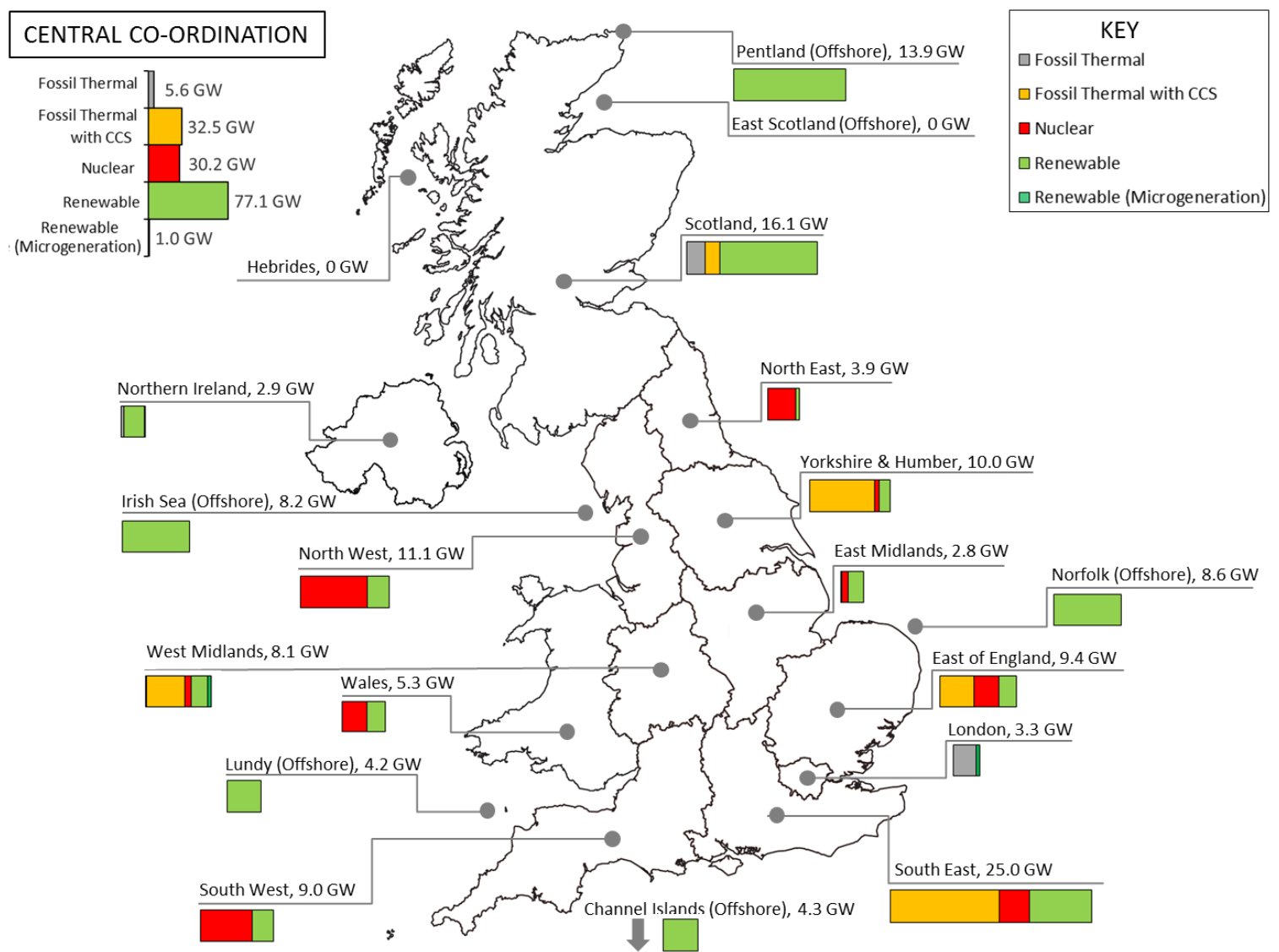

Figure 6 - Central Co-ordination, geographical distribution of cumulative electricity system investments to 2050

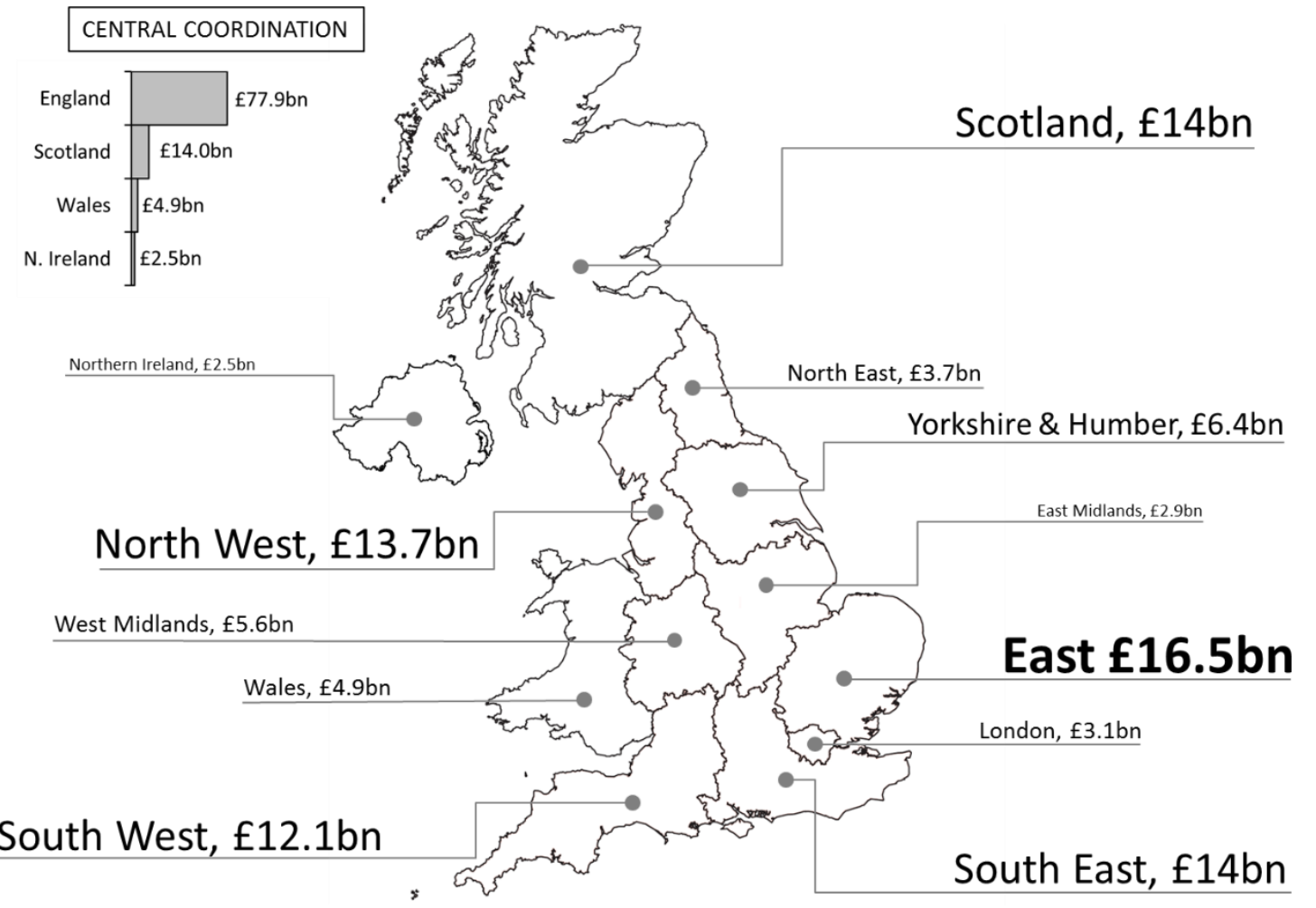


The Thousand Flowers storyline features the highest levels of energy efficiency and has a significant fraction of future heat demand met by bioenergy CHP rather than through electrification (Section 2.3). End-use demand for electricity is therefore the lowest out of the three scenarios assessed. However, due to the assumed intermittent operation of many of the supply sources, such as solar PV and wind energy, the total installed capacity is actually slightly higher than that found in Central Co-ordination (Section 3.2).

Thousand Flowers involves the significant deployment of micro-generation technologies, particularly solar photovoltaics and micro-CHP, as well community-scale bioenergy CHP and some large-scale renewable electricity generation technologies (Figure 7). In contrast to other narratives, where most fossil thermal generation with CCS is found on the East coast, CCS plant in Thousand Flowers is found in nearly all regions. As a result, Thousand Flowers implies a more extensive $\mathrm{CO}_{2}$ transmission system than either Market Rules or Central Co-ordination. Analysis of seasonal and diurnal demand supply matching in ESME reveals that the CCS generation is mainly being used for baseload electricity supply rather than as peaking plant. Scotland and the South East of England are the two regions which require the highest levels of investment in this scenario (Figure 8). 
Figure 7 - Thousand Flowers, geographical distribution of electricity generation capacity by type in 2050

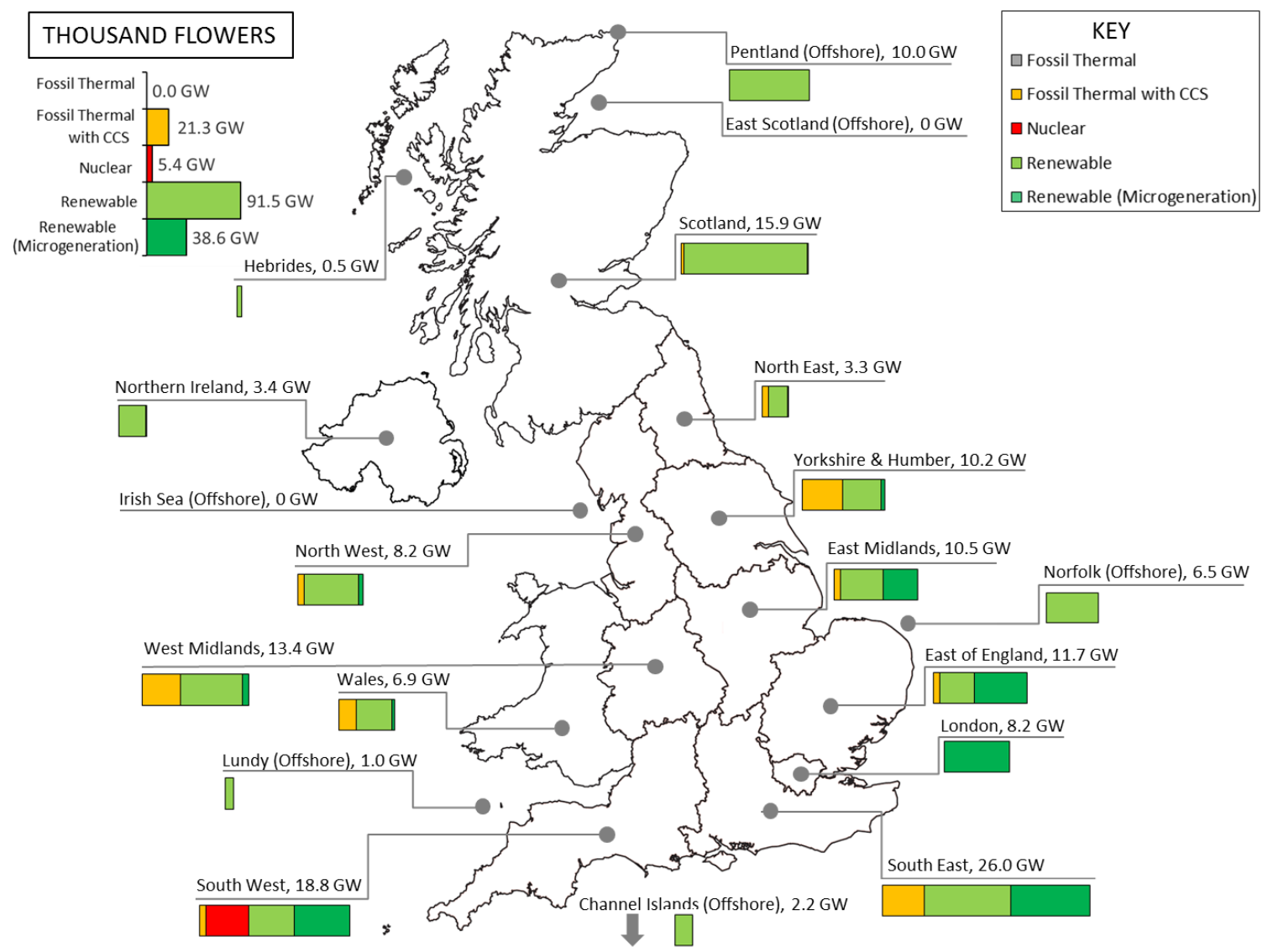

Figure 8 - Thousand Flowers, geographical distribution of cumulative electricity system investments to 2050
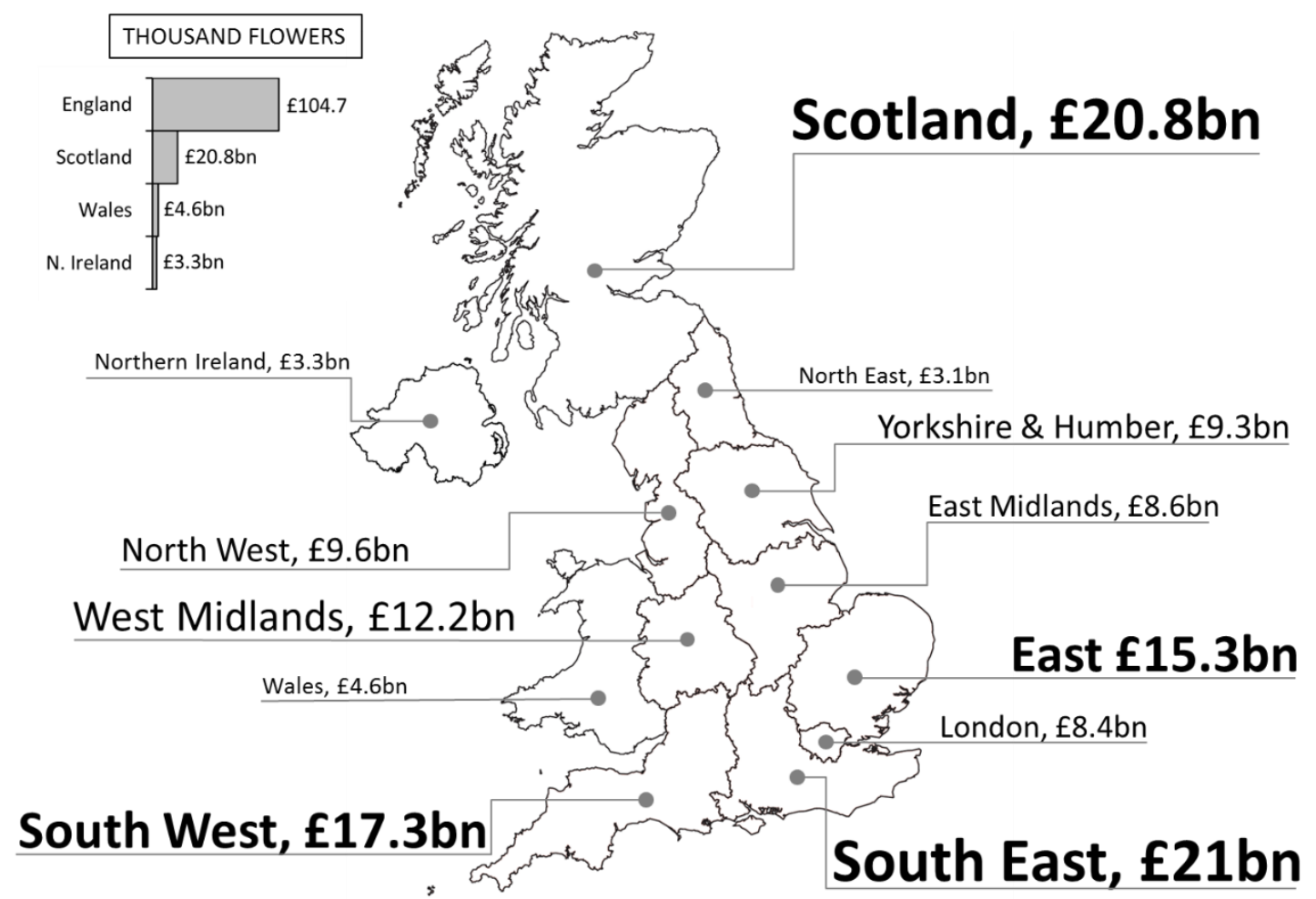
The process of adapting the Realising Transition Pathways scenarios into a spatially explicit whole system energy model for the UK yields a number of insights regarding the feasibility of the original narratives for meeting UK climate targets, the total investment costs implied under each transition, the distribution of costs spatially and between stakeholders, and the physical siting of new technologies. These geographical features all have different implications for governments and local communities.

\subsection{Pathway feasibility}

As noted at the start of Section 3.0, all scenarios required bioenergy sequestration technologies to achieve UK climate targets for 2050. As none of the original Realising Transition Pathways scenarios (Section 2.3) include bioenergy sequestration within the electricity sector, this technology was employed in the model principally for creating alternative decarbonised energy carriers such as hydrogen and biofuels. Sequestration levels in all scenarios were under $100 \mathrm{MtCO}_{2} /$ annually by 2050, which can be considered small relative to the UK's estimated offshore sequestration potential of $78 \mathrm{Gt}$ [107]. A dependence on negative emissions technologies to achieve very deep emissions reduction targets within 30-40 years is a common result in many energy system studies [108] and the UK is no exception [97]. One potential alternative to sequestration to achieve targets would be for the UK to contribute to global climate mitigation efforts through extraterritorial measures such as pursing mitigation options in other countries (e.g. afforestation through emission credit purchases) but an assumption of decarbonisation through domestic action was employed in this paper in line with the government's own ambitions.

The model results presented here rely on levels of bioenergy that are at the high end of the range considered by the Committee on Climate Change $[109,110]$, around 500 TWh (1800 PJ). This implies that the Realising Transition Pathways scenarios can be considered as being consistent with UK climate targets if there are significant levels of bioenergy imports from overseas, or if land use conversion for energy crop cultivation can be achieved in a sustainable fashion beyond the extent explored to date by the CCC. The future availability of bioenergy imports to the UK is complex to estimate and beyond the scope of this paper, depending on future global trade patterns, the level of climate policy ambition found in other countries, and their reliance on bioenergy for domestic use. Interested readers should refer to work by Slade et al. on global bioenergy resource uncertainties [111] and how this may affect the UK more specifically $[112,113]$.

\subsection{Regional investment}

Table 2 compares per capita investment levels, generation capacity additions, and the dominant technologies per region found in each scenario against regional socioeconomic data. This includes measures of gross household disposable income (GDHI), unemployment, and the percentage of the population living outside of major urban areas. Regions in Table 2 are arranged by income/capita in descending order so that the wealthiest areas are at the top, and the most economically disadvantaged at the bottom. The inclusion of a measure of rural population stems from the observation that rural 
areas pose particular challenges to economic development. They often do not have the critical mass of population and transport links to develop economies of scale and attract a wide range of industries. Regional infrastructure development projects can therefore be viewed as highly desirable as they drive investment flow and can create opportunities for employment and wealth creation in the areas where they are located. The use of simple metrics such as jobs/MW has been shown to be problematic [114] and is not attempted here, but it is clear that investment brings positive benefits. At the same time, there can be negative impacts from infrastructure projects, such as visual siting of industrial plant and transmission lines that change the aesthetics of historically agrarian or woodland areas.

Table 2 - Summary comparison of regional socioeconomic data and key evaluation metrics

\begin{tabular}{|c|c|c|c|c|}
\hline $\begin{array}{l}\text { Region }^{1} \text {, } \\
\text { Income/Capita }{ }^{2} \text {, Rural } \\
\text { Unemployment }^{3} \text {, } \\
\text { Rural Population }^{4}\end{array}$ & $\begin{array}{c}\text { Investment ( } \mathrm{f} / \text { Capita) } \\
\text { Capacity (GWe) }\end{array}$ & Market Rules & $\begin{array}{c}\text { Central } \\
\text { Co-ordination }\end{array}$ & $\begin{array}{l}\text { Thousand } \\
\text { Flowers }\end{array}$ \\
\hline \multirow{4}{*}{$\begin{array}{l}\text { London } \\
\text { Income/capita: } £ 20,475 \\
\text { Unemployment: } 9.7 \% \\
\text { Rural Population: } 0.2 \%\end{array}$} & Investment, Electricity & 247 & 373 & 1,011 \\
\hline & Investment, All Energy & 1,324 & 1,240 & 2,325 \\
\hline & Generation Capacity & 5.9 & $3 \cdot 3$ & 8.2 \\
\hline & Dominant Technologies & Fossil Thermal & Fossil Thermal & Renewable Energy \\
\hline \multirow{4}{*}{$\begin{array}{l}\text { South East } \\
\text { Income/capita: } £ 18,124 \\
\text { Unemployment: } 6.3 \% \\
\text { Rural Population: } 20.4 \%\end{array}$} & Investment, Electricity & 1,406 & 1,602 & 2,412 \\
\hline & Investment, All Energy & 2,359 & 2,605 & 3,175 \\
\hline & Generation Capacity & 24.6 & 25.0 & 26.0 \\
\hline & Dominant Technologies & Fossil Thermal CCS & Fossil Thermal CCS & Renewable Energy \\
\hline \multirow{4}{*}{$\begin{array}{l}\text { East of England } \\
\text { Income/capita: } £ 16,743 \\
\text { Unemployment: } 6.9 \% \\
\text { Rural Population: } 28.9 \%\end{array}$} & Investment, Electricity & 2,717 & 2,787 & 2,593 \\
\hline & Investment, All Energy & 4,927 & 4,838 & 4,185 \\
\hline & Generation Capacity & 24.8 & 18.0 & 18.2 \\
\hline & Dominant Technologies & Fossil Thermal CCS & Offshore Renewables & Renewable Energy \\
\hline \multirow{4}{*}{$\begin{array}{l}\text { South West } \\
\text { Income/capita: } £ 16,049 \\
\text { Unemployment: } 6.6 \% \\
\text { Rural Population: } 31.6 \%\end{array}$} & Investment, Electricity & 2,417 & 2,261 & 3,234 \\
\hline & Investment, All Energy & 3,924 & 3,982 & 5,291 \\
\hline & Generation Capacity & 26.7 & 17.6 & 22.0 \\
\hline & Dominant Technologies & Offshore Renewables & Offshore Renewables & Renewable Energy \\
\hline \multirow{4}{*}{$\begin{array}{l}\text { Scotland } \\
\text { Income/capita: } £ 15,427 \\
\text { Unemployment: } 8.0 \% \\
\text { Rural Population: } 18.4 \%\end{array}$} & Investment, Electricity & 3,590 & 2,648 & 3,923 \\
\hline & Investment, All Energy & 5,212 & 3,188 & 3,839 \\
\hline & Generation Capacity & 43.4 & 30.0 & 26.4 \\
\hline & Dominant Technologies & Offshore Renewables & Offshore Renewables & Renewable Energy \\
\hline \multirow{4}{*}{$\begin{array}{l}\text { East Midlands } \\
\text { Income/capita: } £ 14,371 \\
\text { Unemployment: } 8.0 \% \\
\text { Rural Population: } 26.7 \%\end{array}$} & Investment, Electricity & 566 & 643 & 1,886 \\
\hline & Investment, All Energy & 1,433 & 1,388 & 2,560 \\
\hline & Generation Capacity & 6.4 & 2.8 & 10.5 \\
\hline & Dominant Technologies & Renewable Energy & Renewable Energy & Renewable Energy \\
\hline \multirow{4}{*}{$\begin{array}{l}\text { North West } \\
\text { Income/capita: } 114,220 \\
\text { Unemployment: } 8.5 \% \\
\text { Rural Population: } 10.6 \%\end{array}$} & Investment, Electricity & 1,632 & 1,933 & 1,350 \\
\hline & Investment, All Energy & 3,926 & 4,014 & 3,151 \\
\hline & Generation Capacity & $17 \cdot 5$ & 19.3 & 8.2 \\
\hline & Dominant Technologies & Offshore Renewables & Nuclear Power & Renewable Energy \\
\hline \multirow{4}{*}{$\begin{array}{l}\text { West Midlands } \\
\text { Income/capita: } £ 14,012 \\
\text { Unemployment: } 8.9 \% \\
\text { Rural Population: } 15.1 \%\end{array}$} & Investment, Electricity & 981 & 994 & 2,154 \\
\hline & Investment, All Energy & 2,198 & 2,038 & 2,472 \\
\hline & Generation Capacity & 16.1 & 8.1 & 13.4 \\
\hline & Dominant Technologies & Fossil Thermal CCS & Fossil Thermal CCS & Renewable Energy \\
\hline
\end{tabular}




\begin{tabular}{|c|c|c|c|c|}
\hline \multirow{4}{*}{$\begin{array}{l}\text { Yorkshire \& Humber } \\
\text { Income/capita: }: 13,847 \\
\text { Unemployment: } 10.3 \% \\
\text { Rural Population: } 17.5 \%\end{array}$} & Investment, Electricity & 1,368 & 1,195 & 1,744 \\
\hline & Investment, All Energy & 4,328 & 4,075 & 4,383 \\
\hline & Generation Capacity & $13 \cdot 3$ & 10.0 & 10.2 \\
\hline & Dominant Technologies & Fossil Thermal CCS & Fossil Thermal CCS & Renewable Energy \\
\hline \multirow{4}{*}{$\begin{array}{l}\text { Wales } \\
\text { Income/capita: } ₫ 13,740 \\
\text { Unemployment: } 9.3 \% \\
\text { Rural Population: } 32.8 \%\end{array}$} & Investment, Electricity & 1,578 & 1,591 & 1,481 \\
\hline & Investment, All Energy & 1,456 & 1,898 & 1,870 \\
\hline & Generation Capacity & 5.4 & 5.3 & 6.9 \\
\hline & Dominant Technologies & Nuclear Power & Nuclear Power & Renewable Energy \\
\hline \multirow{4}{*}{$\begin{array}{l}\text { North East } \\
\text { Income/capita: } \neq 13,587 \\
\text { Unemployment: } 11.6 \% \\
\text { Rural Population: } 18.4 \%\end{array}$} & Investment, Electricity & 683 & 1,403 & 1,175 \\
\hline & Investment, All Energy & 1,431 & 1,912 & 1,676 \\
\hline & Generation Capacity & 3.4 & 3.9 & 3.3 \\
\hline & Dominant Technologies & Nuclear Power & Nuclear Power & Renewable Energy \\
\hline \multirow{4}{*}{$\begin{array}{l}\text { Northern Ireland } \\
\text { Income/capita: } ₫ 13,326 \\
\text { Unemployment: } 7.1 \% \\
\text { Rural Population: } 35 \%\end{array}$} & Investment, Electricity & 1,550 & 1,395 & 1,843 \\
\hline & Investment, All Energy & 1,814 & 1,955 & 2,152 \\
\hline & Generation Capacity & 3.1 & 2.9 & 3.4 \\
\hline & Dominant Technologies & Renewable Energy & Renewable Energy & Renewable Energy \\
\hline
\end{tabular}

1 Offshore regions have data allocated to onshore region where infrastructure makes landfall

2,3,4 Gross Disposable Household Income, Rural Population [115] and Unemployment [116] data are based on 2011 Census information from the UK Office of National Statistics, The Scottish Government, and The Northern Ireland Statistics and Research Agency (NSRIA)

Figure 9 and Figure 10 both use data from Table 2 to provide two graphical crosscomparisons of the differences in cumulative regional investment costs into the electricity system in the period to 2050. Figure 9 allows an easier visualisation of the changes in total investment levels between scenarios while Figure 10 provides a clear view on the different geographical distribution patterns. From these two visualisations it can be seen that Market Rules and Central Coordination have regional patterns of investment that are broadly similar to one another, while Thousand Flowers is significantly different. 
Figure 9 - Cumulative electricity system investment per capita to 2050, by region, line chart

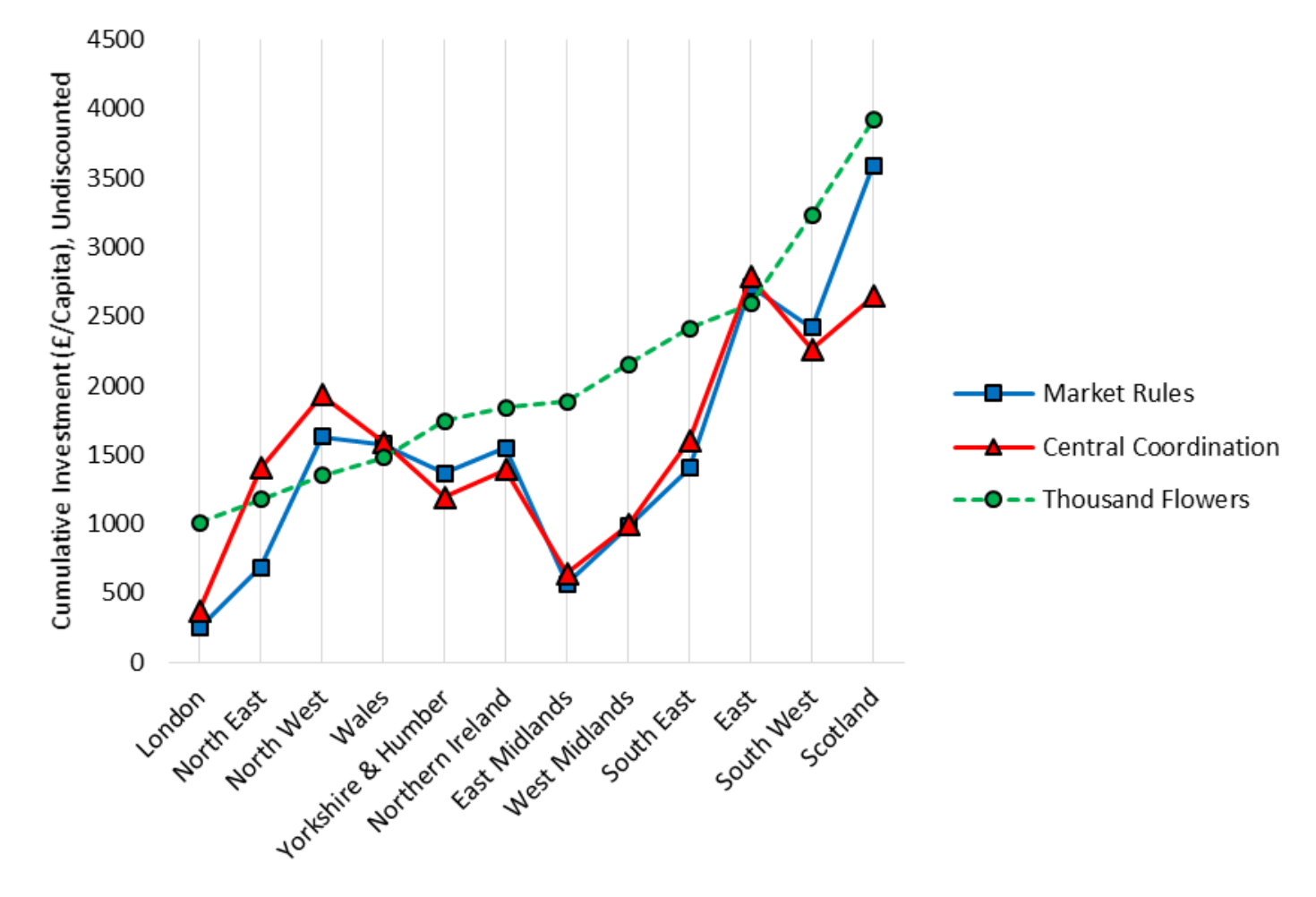

Figure 10 - Cumulative electricity system investment per capita to 2050, by region, gradient map

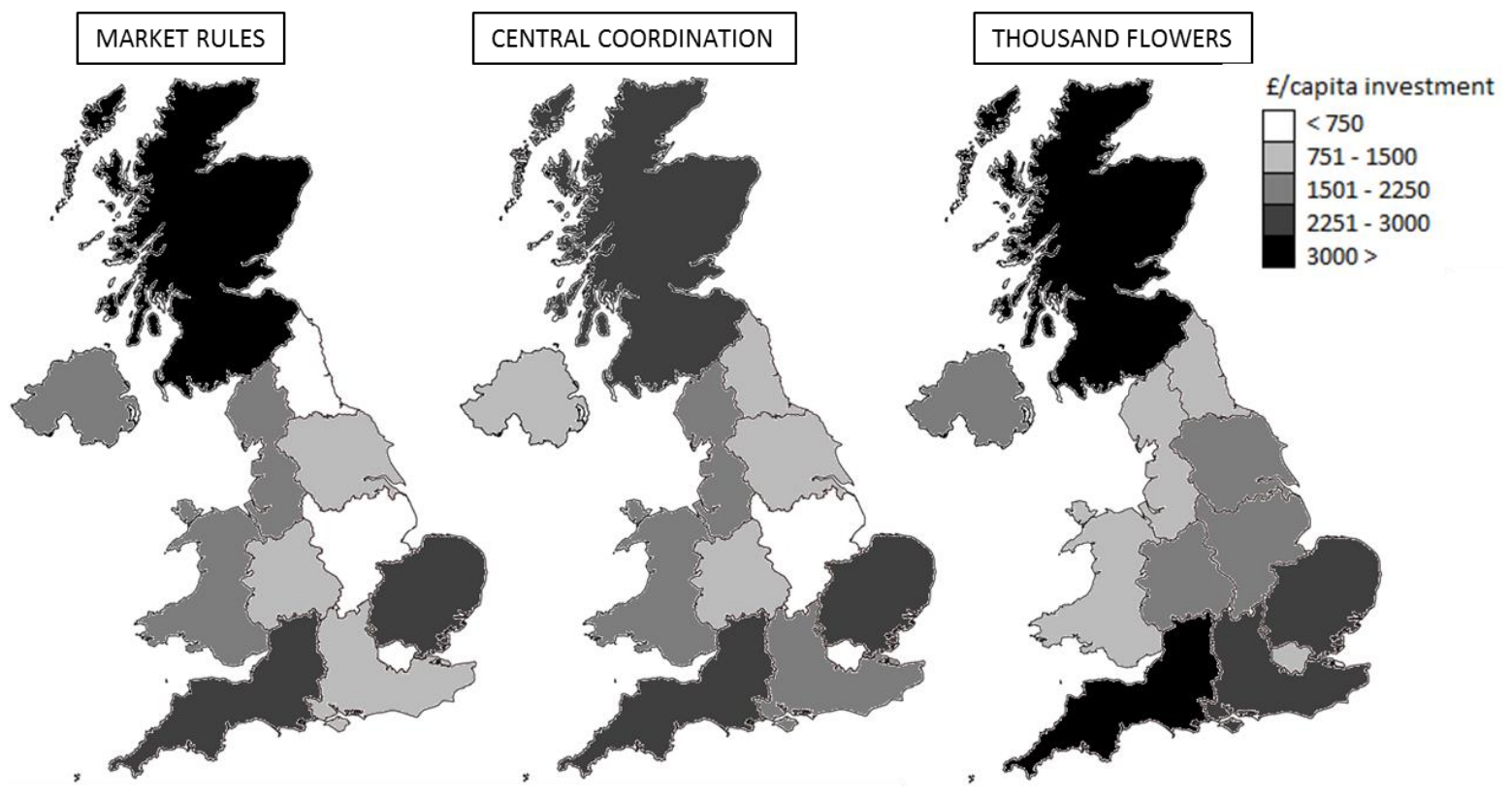


Figure 11 represents the underlying technological differences between the scenarios that cannot necessarily be observed from an analysis of investment levels. It can be seen that Market Rules and Central Co-ordination employ a similar balance of technologies overall. However, Market Rules relies on a greater proportion of offshore marine and wind resources which are abundant in the South West and Scotland, as well as more carbon capture and storage plants, particularly in the West Midlands and the East of England. Compared with Market Rules, the Central Co-ordination scenario invests a greater proportion of resources into developing nuclear power in England and Wales, which draws investment away from Scotland and the South West. Thousand Flowers, as might be expected, is radically different to both of the other cases with its focus on renewables and a more land-based deployment of technologies. Thousand Flowers sees English regions, particularly in the South of the country, dominating investment in new plant capacity, but also a shows a strong role for Scotland.

Figure 11 - Regional electricity generation outlook for all scenarios, bar chart
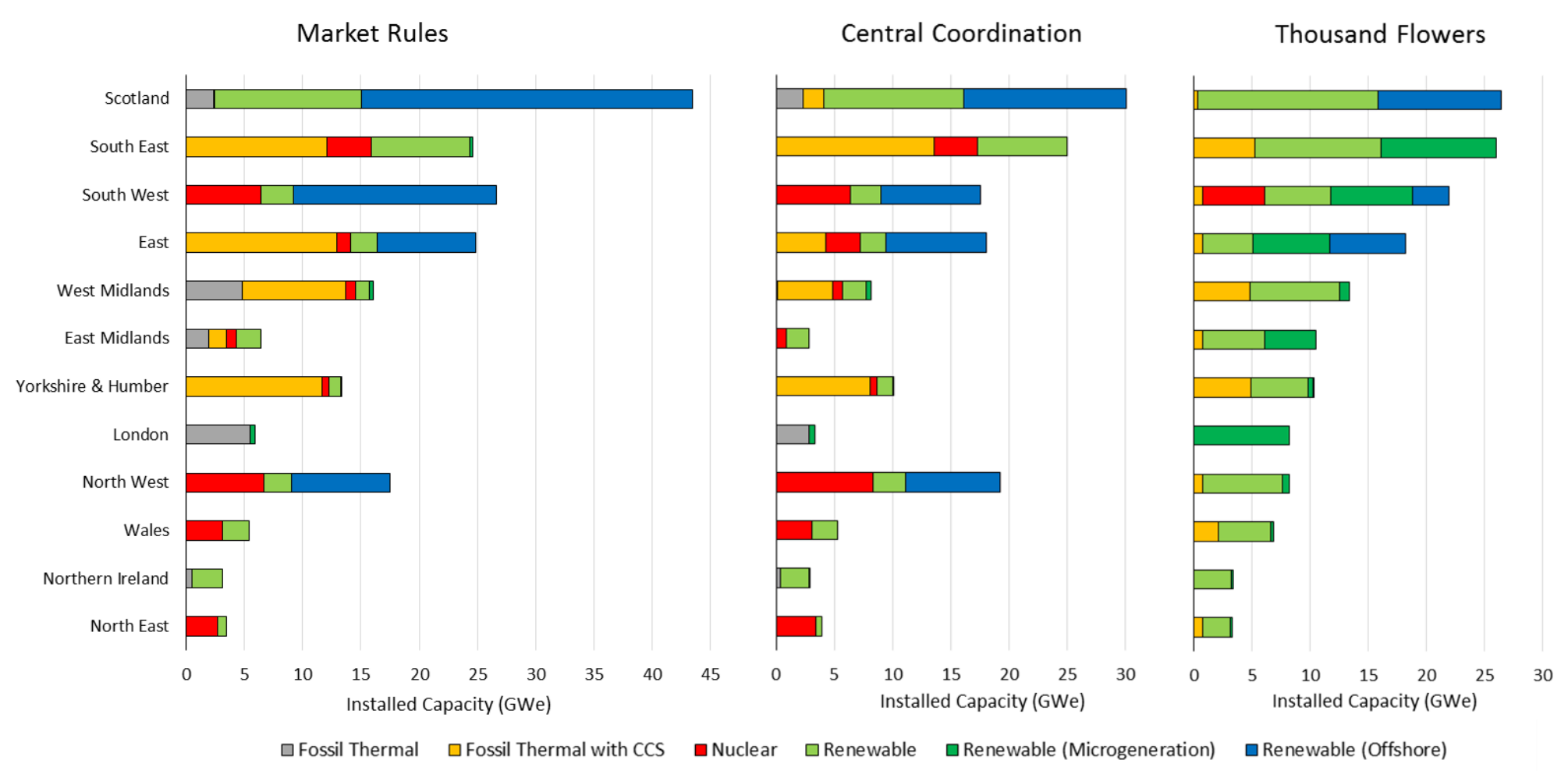
Before embarking on a discussion of regional winners and losers, we finally consider energy infrastructure investments outside of the electricity sector. A strength of using a whole system model such as ESME is that all energy infrastructure, including electricity, heat, natural gas, bioenergy, hydrogen, and $\mathrm{CO}_{2}$ can be explored under the same analytical framework. While it is true that the electricity system is the most critical in the UK case for a transition to a low carbon future, and merits the level of detailed analysis we have illustrated here, it is important also not to ignore infrastructure requirements for these other energy vectors when exploring regional differences. Figure 12 illustrates a ranking of regional investment required in all energy infrastructure.

Figure 12 - Cumulative energy infrastructure investments per capita by region, line chart

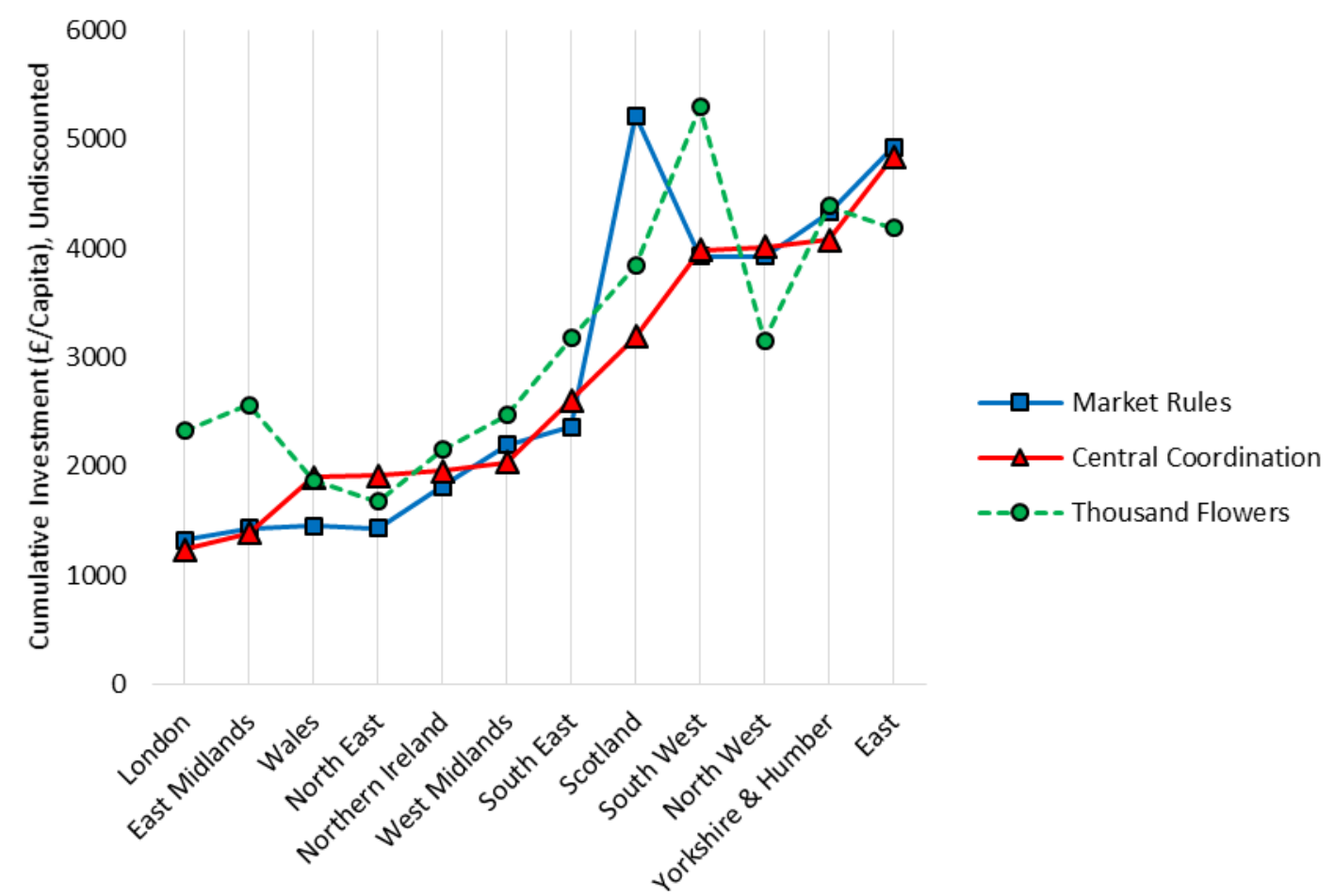

Returning to the title of this paper, which regions appear to emerge as the potential winners and losers under these transitions? Assuming that economic development is a priority, that a clear link between infrastructure deployment and regional wealth creation can be made (see Section 4.5 for further discussion), and that negative impacts can be sufficiently mitigated in all cases, then we can draw some firm conclusions. London and the South East of England are the wealthiest regions of the UK (see Table 2) and have highly diversified economies, so the outcomes in terms of energy infrastructure are less crucial to their future economic development. However, Wales, the North East, and Northern Ireland all rank at the bottom of the pack in terms of UK income per capita, and the North East in particular has the highest levels of unemployment and the weakest regional economy in the country in terms of GVA/capita [117]. These three regions, together with the East Midlands, stand to lose out under all of the scenarios assessed in this paper, receiving per capita investment levels around five times lower than rival regions who benefit the most from the transition. 
Who are the winners? The East of England consistently receives high levels of investment across all three scenarios, as do Yorkshire and Humber and the North West. While these latter two regions actually rank towards the bottom of the pack in terms of their electricity system investments (see Figure 9), their importance as coastal regions with access to carbon capture and sequestration infrastructure means that they become important centres for biofuel and hydrogen production in all scenarios. As can be seen from Table 2, Yorkshire and the North West both fall at the lower end of the UK wealth spectrum, and have been historically blighted by high unemployment. The outcomes modelled here under would represent an economic boon for these areas. The East of England, while not one of the UK's poorest regions, has a large rural population and one that is highly agricultural in character. The results from the model analysis imply that this area could become an important region for energy industries of all types, diversifying its economic base. Scotland and the South West are also regions that see strong inward investment in energy infrastructure, with Scotland benefitting particularly strongly under Market Rules, and the South West under Thousand Flowers. These regions would benefit from economic diversification in the same way as the East of England. The South West is currently highly dependent on tourism while significant parts of Scotland rely on heavily on both tourism and the offshore oil and gas industry.

\subsection{Affordability, equity and public attitudes}

Energy affordability is a key concern for the public, and the total costs of any energy transition may be just as important as their regional impacts. Different actors are responsible for making the investments in each narrative, but regardless of how capital is allocated under each scenario, householders ultimately bear the costs in some form, whether through direct investment, taxation or utility payments. Figure 13 shows the modelled cumulative investments into the energy system to 2050 required for different definitions of the system boundary. These can be viewed as a proxy for the affordability of the transition in each case. Market Rules and Central Co-ordination show very similar investment levels for all system boundaries. Thousand Flowers requires the highest investments. This corroborates the findings from a previous assessment of transition costs for the three pathways [93].

A detailed breakdown of these investments will the subject of future publications, and an initial cross-comparison of sectoral transitions between Central Co-ordination and Thousand Flowers can be found in a recent publication by Li [98]. Briefly however, the modelled electricity system for Thousand Flowers has a higher carbon intensity than the other scenarios, due to its strong reliance on bioenergy, which ESME (unlike many ESOMs) treats as having a residual $\mathrm{CO}_{2}$ content i.e. the model considers energy used in the cultivation, processing, and transport of the fuel to power plants.

As modelled therefore, the power sector mix under Thousand Flowers is very low carbon, but not zero carbon, unlike Central Co-ordination and Market Rules. The carbon content of future UK bioenergy resources is complex to estimate and is not explored further here, as it has been discussed at length in other work e.g. [118]. The higher residual emissions from the power sector in Thousand Flowers compared to the other scenarios, as well as the lower level of electrification in general (Section 2.3), means that in order to reach GHG reduction targets for 2050 the model must make proportionately higher investments in decarbonising other sectors, particularly transport. 
Figure 13 - Cumulative investment to 2050 for each narrative under different system boundaries

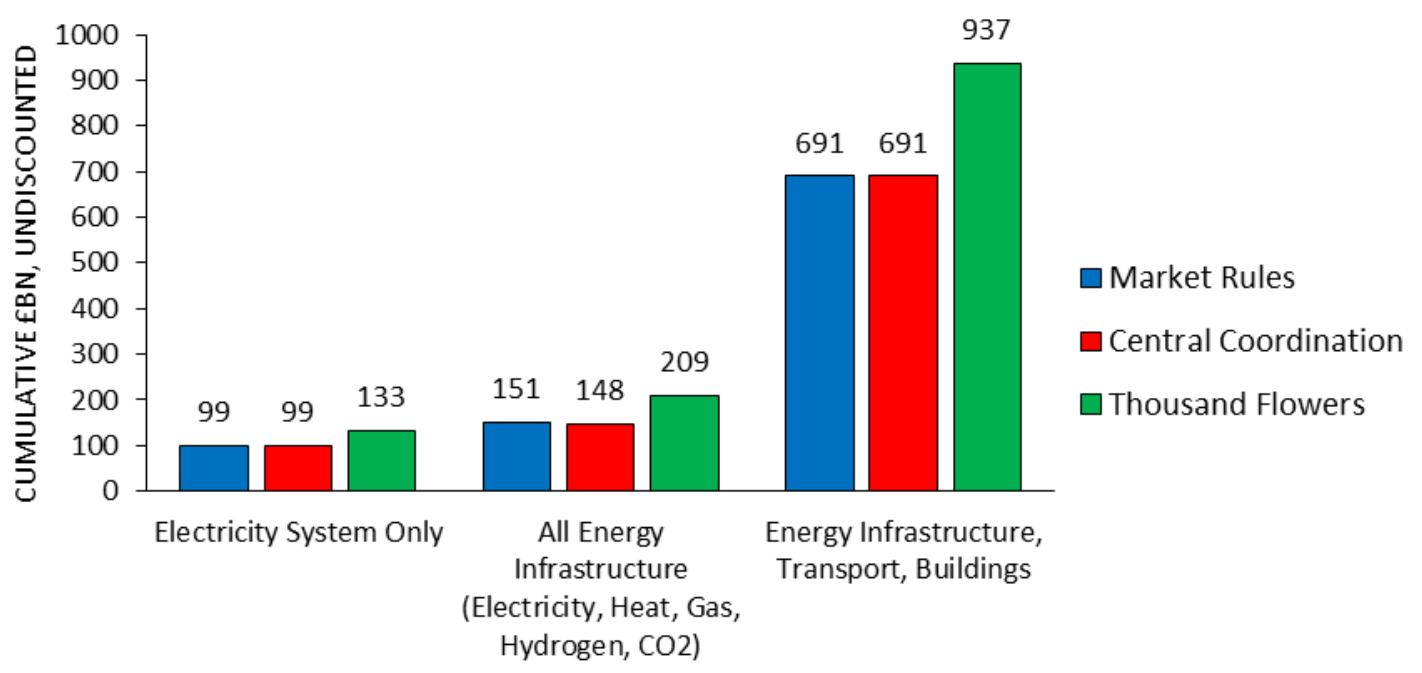

How the higher costs of transition in Thousand Flowers might affect the viability of this scenario in the eyes of consumers is difficult to directly infer. A recent global metaanalysis of 30 willingness-to-pay studies with 137 estimates suggests that consumers are actually willing to pay more for renewable electricity, but that the exact premium varies between national contexts [119]. German customers for example, may be willing to pay a premium (as high as 16\%) for renewable electricity from community energy groups $[120,121]$. Studies commissioned by the UK's statutory consumer protection body suggest that while there is a degree of correlation between income and willingness to pay for environmental protection, consumers are broadly willing to pay more towards the costs of an energy transition as long as government and corporations are seen to be also contributing fairly [122].

As well as affordability issues, the public acceptability of different energy technologies and the direct impacts on communities may also play a large part in any future energy transition. Investments in energy infrastructure, like power stations, are often politicised at a local level. UK research has yet to draw any firm conclusions about community attitudes towards different technologies, which are likely to be heterogeneous and subject to change through time. Clearly, there are also complex nuances to attitudes that go beyond a binary support/reject characterisation. For example, recent UK research into the public acceptability of different energy technologies has shown strong support for wind and solar energy [123] in principle, but this has not prevented significant objections to onshore wind farms being placed near communities [124].

\subsection{Implications for policy}

At the time of writing, there is a spectrum of policy autonomy between UK regions regarding energy policy, with Northern Ireland having effective full control, Wales having the least formal powers, and Scotland being somewhere in-between [125]. The presented analysis shows that Scotland will benefit under all scenarios but also stands to gain or lose significantly depending on the choice of transition pathway (Section 4.2). In Scotland, the central UK government currently retains fiscal and legislative powers pertaining to energy generation, transmission and distribution, but the devolved Scottish administration has control over environmental regulation and planning as well 
as specific powers to approve or block power stations above certain sizes $[126,127]$. As noted in Section 1.4, Scotland also has a set of climate and energy targets that are separate from those of the rest of the UK and has imposed a moratorium on new nuclear power stations on its territory. The Scottish government is also very open about its intention to seek a UK-wide regulatory regime that will promote the use of its abundant renewable energy resources [128].

All three scenarios show Scotland having very high investment in the electricity system relative to the population. A high degree of policy coordination between the Scottish government and the UK Parliament may therefore be required in future. A prominent role for Scotland in national energy policy would also need to be politically acceptable for the rest of the UK. At present, intergovernmental relations between Scotland and the UK Parliament are essentially ad hoc, with no explicit mechanisms to ensure long-term policy coordination [56]. Both the Central Coordination and Market Rules scenarios imply that the UK government successfully secures buy-in from communities in England and Wales for the construction of large numbers of new and possibly unpopular nuclear power stations, while Scotland remains nuclear-free. Nuclear power has historically been deeply divisive in the UK, but studies suggests that the public may reluctantly support nuclear power if the government successfully frames other options as having been exhausted $[129,130]$.

The Thousand Flowers narrative implies a largely nuclear-free future, but would require a strong shift in attitudes towards the community ownership of generation, along the lines of the German model, where almost $50 \%$ of renewable energy assets are in community hands [131]. Public support would be particularly critical in light of the significantly higher transition costs implied by this pathway (Figure 13). Government would need to signal strong support for such a transition in order to incentivise citizen and investor participation for the financing of community energy projects. Policies to reduce or eliminate information asymmetry between community-owned and corporate utilities regarding planning and permitting for new schemes, widening the remit of existing feedin-tariff schemes to cover larger installations [132], and a relaxation of licencing conditions for locally owned generation [133] are all examples of mechanisms that the government might take in this case.

\subsection{Developing future insights}

There are many possible directions for extending the analysis of energy transition impacts at the regional level based on the work presented in this paper. While investment distribution was assessed for all energy infrastructure (Figure 12), technology siting was only mapped for the power sector (Section 3.0). One obvious extension of this work would be to perform spatial mapping of technology deployment for gas, bioenergy, hydrogen and $\mathrm{CO}_{2}$. Another would be to expand the scope of the analysis further to explore regional economic restructuring and employment effects. ESME does not endogenously represent macro-economic feedbacks between the energy system and different economic sectors, so the impacts on factors such as production, consumption and consumer welfare, for example, cannot be directly observed in the model outputs presented so far. This in turn, makes discussion of strategies for promoting regional economic development, wealth redistribution, and the politics of addressing inequalities between competing regions particularly difficult without further modelling and analysis. 
The employment effects of energy system transformation are one area that is acknowledged as being complex to model $[134,135]$. One challenge is that over long time periods, economic factors such as labour and capital assets can be relocated to where they are needed, and workers can also travel across regional boundaries to seek employment. Long term trends in population demographics, such as age structure and migration between regions would need to be taken into account. Another complexity is that factories producing components for the energy transition do not necessarily need to be located in the regions where they will eventually be installed, provided that transport links are sufficiently strong. Understanding how each of the energy transition scenarios might drive regional changes in economic activity and employment would require ESME outputs to be coupled to a full regional macroeconomic model as well as detailed data on industrial supply chains. The negative impacts of constructing energy system infrastructure on industries like tourism would also need to be fully understood and integrated into this future work.

\subsection{Conclusions}

This paper demonstrates the latest step in a long running process of UK science-policy engagement. Detailed narratives about the future of the UK energy system and specifically, the electricity sector, built up over several years in consultation with UK government, industry, and civil society stakeholders were reflected in a leading whole economy energy systems model with explicit representation of sub-national regions. This provided a test environment to explore the feasibility of the scenario narratives as well as allowing the interactions between the stakeholder visions for the power system and other economic sectors to be explored using the rich technological detail of the model. The sub-national regional characterisation of the model was used to explore how the geographical distribution of technologies and their costs might be distributed under each scenario, with the results discussed in the context of the complex regional political geography of the UK.

From a technical feasibility perspective, a key finding is that the Realising Transition Pathways scenarios rely on levels of bioenergy that are at the high end of published estimates. The scenarios require an assumption that significant volumes of bioenergy will be imported to the UK in future in order for them to be compatible with achieving the UK's national climate policy targets for 2050. The use of bioenergy with carbon capture and storage features strongly in the model solutions, often outside of the power sector for end-use fuel production.

The geographical analysis presented here demonstrates the type of insights into regional technology deployment and costs at a sub-national level which are difficult to achieve with nationally aggregated models. The main strategic insight for governments and communities that arises from this analysis is that the sub-national distribution of energy transition costs can vary significantly depending on the choice of decarbonisation pathway taken. Future technology choices in the power sector bring with them strong regional implications for future investment targeting, suggesting the possibility of there being regional winners and losers under different transitions.

Under a broad range of technological scenarios, the East of England, the North West, Yorkshire and Humber, Scotland, and the South West all emerge as "winners". These 
regions receive large per-capita investments that have the potential to both drive wealth creation in historically disadvantaged areas as well as diversify economic activity. The East Midlands, the North East of England, Wales and Northern Ireland all emerge as "losers" from the energy transitions modelled here. While in absolute terms there are large investments in all of these areas, they receive much less in per capita investment terms than other regions of the country. The North East stands out in particular as an area with the UK's highest levels of unemployment and the second lowest per capita income. The question of whether the energy transition can be used as a vehicle to promote regional economic development in disadvantaged areas remains highly topical, but requires further analysis with regional macroeconomic modelling and supply chain assessment. Future work will assess the scope for regional economic policies that develop supply chains to meet the needs of future energy transitions while increasing opportunities for inward investment in marginal areas.

The mapping of economic costs to individual regional actors (e.g. specific power companies) is difficult to identify conclusively from this analysis, but clearly it is possible that actions which maximise local investment in a given region (e.g. the North East) might have the simultaneous effect of raising overall costs across the whole system. This begins to illustrate some of the complexities surrounding the delivery of an equitable energy transition, where local action to benefit one community may simultaneously disadvantage other communities or actually present affordability challenges for all.

In terms of overall affordability, the two pathways involving the most electrification and the most large-scale centralised generation plant, Central Co-ordination and Market Rules, were found to require the lowest investment costs in the period to 2050, while the distributed energy pathway, Thousand Flowers, involved the highest costs. The choice of decarbonisation strategy for the power sector in Thousand Flowers is found to have knock-on effects that require additional investments in the transport sector, an insight which can only be shown through integrated analysis using a whole system model.

From a policy perspective, the study results point to co-ordination between different governments, particularly between the central UK Government in London and the Scottish Government in Edinburgh, as being important to influencing the character of the transition to a low carbon energy system. Across the assessed scenarios, Scotland emerges as a renewable energy powerhouse requiring high levels of per-capita investment in the energy system, and also escapes a requirement to host nuclear power stations on its territory. It remains to be seen whether politicians can address the perceptions of inequality that this might raise amongst the electorate, particularly as it appears that English regions could lose out more from increased investment in Scotland than Wales or Northern Ireland.

Another important issue raised by the analysis is whether the future interests of the different devolved administrations will push in the same direction, be synergistic with one another, and be consistent with a whole-economy, whole-UK emissions reduction target. At the time of writing, there are no official policy statements on how these differing regions can collaborate together in the mid-term to achieve the UK's long term targets. The distributional impacts of energy transition policies, which parts of society pay and which parts benefit, and what the contribution from individual sub-national regions should be remains a significant unaddressed question in policy terms. What is clear however, is that, without convincingly articulating the sub-national costs, benefits, 
and governance requirements for different energy transition pathways, it is difficult to see how a co-ordinated national-scale decarbonisation plan can be delivered in an affordable and timely fashion, if at all.

Finally, this work demonstrates an effort by energy system modellers to contribute to a wider process of interdisciplinary research, bringing the strengths of quantitative energy economic analysis to a long-running and successful process of socio-technical exploration, expert engagement, and ongoing policy impact. In particular, it shows how taking a formal systems approach can enhance the outputs from other disciplines by: allowing assumptions from different groups to be formalised and shared in a common framework, enabling scenarios to be tested against objectives in a rigorous fashion, and helping researchers with different interests and specialisms to look beyond narrow sectoral boundaries (e.g. power, transport) at cross cutting issues and the wider context for their work.

Interdisciplinary research undoubtedly faces many challenges. It can messy, complex to articulate and difficult to execute in practice. From a modelling perspective, it may challenge positivist notions of solution optimality, mathematical elegance, and disciplinary segregation. However, the authors urge pragmatism in this regard and for the innovative use of energy economy models to advance the state of policy discourse on energy system transitions in collaboration with colleagues from other disciplines. The urgency of the climate policy challenge leaves no other alternative.

\subsection{Acknowledgements}

This paper builds on research carried out under Grant Reference KP/Ko05316/1 'Realising Transition Pathways: Whole Systems Analysis for a UK More Electric Low Carbon Energy Future' Consortium Project funded by the UK Engineering and Physical Sciences Research Council (EPSRC) [under Grant EP/Ko05316/1]. The decision to submit this article for publication was taken by the authors alone. The opinions expressed in the text are those of the authors alone.

\section{References}

[1] P.G. Taylor, P. Upham, W. McDowall, D. Christopherson, Energy model, boundary object and societal lens: 35 years of the MARKAL model in the UK, Energy Res. Soc. Sci. 4 (2014) 32-41. doi:10.1016/j.erss.2014.08.007.

[2] L. Clarke, K. Jiang, K. Akimoto, M. Babiker, G. Blanford, K. Fisher-Vanden, et al., Assessing Transformation Pathways, in: O. Edenhofer, R. Pichs-Madruga, Y. Sokona, E. Farahani, S. Kadner, K. Seyboth, et al. (Eds.), Clim. Chang. 2014 Mitig. Clim. Chang. Contrib. Work. Gr. III to Fifth Assess. Rep. Intergov. Panel Clim. Chang., Cambridge University Press, Cambridge, United Kingdom and New York, NY, USA, 2014: pp. 413-510. https://www.ipcc.ch/pdf/assessmentreport/ar5/wg3/ipcc_wg3_ar5_chapter6.pdf.

[3] D. McCollum, C. Yang, S. Yeh, J. Ogden, Deep greenhouse gas reduction scenarios for California - Strategic implications from the CA-TIMES energy-economic systems model, Energy Strateg. Rev. 1 (2012) 19-32. doi:10.1016/j.esr.2011.12.003.

[4] F. Amorim, A. Pina, H. Gerbelová, P. Pereira da Silva, J. Vasconcelos, V. Martins, 
Electricity decarbonisation pathways for 2050 in Portugal: A TIMES (The Integrated MARKAL-EFOM System) based approach in closed versus open systems modelling, Energy. 69 (2014) 104-112. doi:10.1016/j.energy.2014.01.052.

[5] L. Girardin, F. Marechal, M. Dubuis, N. Calame-Darbellay, D. Favrat, EnerGis: A geographical information based system for the evaluation of integrated energy conversion systems in urban areas, Energy. 35 (2010) 830-840.

doi:10.1016/j.energy.2009.08.018.

[6] T. Ma, P.A. Østergaard, H. Lund, H. Yang, L. Lu, An energy system model for Hong Kong in 2020, Energy. 68 (2014) 301-310. doi:10.1016/j.energy.2014.02.096.

[7] N. Strachan, S. Pye, R. Kannan, The Iterative Contribution and Relevance of Modelling to UK Energy Policy, Energy Policy. 37 (2009) 850-860.

doi:10.1016/j.enpol.2008.09.096.

[8] A. Boston, Delivering a secure electricity supply on a low carbon pathway, Energy Policy. 52 (2013) 55-59. doi:10.1016/j.enpol.2012.02.004.

[9] J.F. DeCarolis, K. Hunter, S. Sreepathi, The case for repeatable analysis with energy economy optimization models, Energy Econ. 34 (2012) 1845-1853. doi:10.1016/j.enec0.2012.07.004.

[10] P.E. Dodds, I. Keppo, N. Strachan, Characterising the Evolution of Energy System Models Using Model Archaeology, Environ. Model. Assess. (2014). doi:10.1007/s10666-014-9417-3.

[11] E. Trutnevyte, Does cost optimization approximate the real-world energy transition?, Energy. (2016). doi:0.1016/j.energy.2016.03.038.

[12] P. Agnolucci, W. McDowall, Designing future hydrogen infrastructure: Insights from analysis at different spatial scales, Int. J. Hydrogen Energy. 38 (2013) 51815191. doi:10.1016/j.ijhydene.2013.02.042.

[13] C. Wilson, H. Dowlatabadi, Models of Decision Making and Residential Energy Use, Annu. Rev. Environ. Resour. 32 (2007) 169-203.

doi:10.1146/annurev.energy.32.053006.141137.

[14] J.A. Laitner, S.J. DeCanio, J.G. Koomey, A.H. Sanstad, Room for improvement: increasing the value of energy modeling for policy analysis, Util. Policy. 11 (2003) 87-94. doi:10.1016/So957-1787(03)00020-1.

[15] D. Helm, C. Hepburn, R. Mash, Credible Carbon Policy, Oxford Rev. Econ. Policy. 19 (2003) 438-450. doi:10.1093/oxrep/19.3.438.

[16] R. Stavins, J. Jaffe, T. Schatzki, Too Good to Be True? An Examination of Three Economic Assessments of California Climate Change Policy, NBER Working Paper 13587, National Bureau of Economic Research (NBER), Cambridge, MA, 2007. doi:10.3386/w13587.

[17] M. Howells, H. Rogner, N. Strachan, C. Heaps, H. Huntington, S. Kypreos, et al., OSeMOSYS: The Open Source Energy Modeling System, Energy Policy. 39 (2011) 5850-5870. doi:10.1016/j.enpol.2011.06.033.

[18] S. Pye, W. Usher, N. Strachan, The uncertain but critical role of demand reduction in meeting long-term energy decarbonisation targets, Energy Policy. 73 (2014) 575-586. doi:10.1016/j.enpol.2014.05.025.

[19] E. Trutnevyte, EXPANSE methodology for evaluating the economic potential of renewable energy from an energy mix perspective, Appl. Energy. 111 (2013) 593601. doi:10.1016/j.apenergy.2013.04.083.

[20] J.F. DeCarolis, Using modeling to generate alternatives (MGA) to expand our thinking on energy futures, Energy Econ. 33 (2011) 145-152. doi:10.1016/j.eneco.2010.05.002. 
[21] G.J. Blanford, E. Kriegler, M. Tavoni, Harmonization vs. fragmentation: overview of climate policy scenarios in EMF27, Clim. Change. 123 (2014) 383-396. doi:10.1007/s10584-013-0951-9.

[22] E. Trutnevyte, J. Barton, Á. O'Grady, D. Ogunkunle, D. Pudjianto, E. Robertson, Linking a storyline with multiple models: A cross-scale study of the UK power system transition, Technol. Forecast. Soc. Change. 89 (2014) 26-42. doi:10.1016/j.techfore.2014.08.018.

[23] C. Lennox, R. Dodder, Cy. Gage, O. Kaplan, D. Loughlin, W. Yelverton, EPA U.S. Nine-region MARKAL Database: Database Documentation, National Risk Management Research Laboratory, Cincinnati, Ohio, USA, 2013. http://nepis.epa.gov/Exe/ZyPDF.cgi/P10ol4RX.PDF?Dockey=P10ol4RX.PDF.

[24] A. Kerimray, K. Baigarin, A. Bakdolotov, R. De Miglio, G. Tosato, Improving Efficiency in Kazakhstan's Energy System, in: G. Giannakidis, M. Labriet, B. Ó Gallachóir, G. Tosato (Eds.), Informing Energy Clim. Policies Using Energy Syst. Model. Lect. Notes Energy 30, Springer International Publishing Switzerland, 2015: pp. 141-150. doi:10.1007/978-3-319-16540-0_8.

[25] I. Keppo, M. Strubegger, Short term decisions for long term problems - The effect of foresight on model based energy systems analysis, Energy. 35 (2010) 20332042. doi:10.1016/j.energy.2010.01.019.

[26] H.E. Daly, K. Ramea, A. Chiodi, S. Yeh, M. Gargiulo, B.Ó. Gallachóir, Incorporating travel behaviour and travel time into TIMES energy system models, Appl. Energy. 135 (2014) 429-439. doi:10.1016/j.apenergy.2014.08.051.

[27] F.G.N. Li, Actors behaving badly: modelling non-optimal behaviour in energy transitions, in: 35th Int. Energy Work. (IEW 2016), Cork, Ireland, 2016.

[28] D.L. McCollum, C. Wilson, H. Pettifor, K. Ramea, V. Krey, K. Riahi, et al., Improving the behavioral realism of global integrated assessment models: An application to consumers' vehicle choices, Transp. Res. Part D Transp. Environ. (2016). doi:10.1016/j.trd.2016.04.003.

[29] R. Fouquet, The slow search for solutions: Lessons from historical energy transitions by sector and service, Energy Policy. 38 (2010) 6586-6596. doi:10.1016/j.enpol.2010.06.029.

[30] P.J.G. Pearson, T.J. Foxon, A low carbon industrial revolution? Insights and challenges from past technological and economic transformations, Energy Policy. 50 (2012) 117-127. doi:10.1016/j.enpol.2012.07.061.

[31] N. Hughes, N. Strachan, Methodological review of UK and international low carbon scenarios, Energy Policy. 38 (2010) 6056-6065. doi:10.1016/j.enpol.2010.05.061.

[32] S. Pfenninger, A. Hawkes, J. Keirstead, Energy systems modeling for twenty-first century energy challenges, Renew. Sustain. Energy Rev. 33 (2014) 74-86. doi:10.1016/j.rser.2014.02.003.

[33] J. Markard, R. Raven, B. Truffer, Sustainability transitions: An emerging field of research and its prospects, Res. Policy. 41 (2012) 955-967. doi:10.1016/j.respol.2012.02.013.

[34] E.J.L. Chappin, A. Ligtvoet, Transition and transformation: A bibliometric analysis of two scientific networks researching socio-technical change, Renew. Sustain.

Energy Rev. 30 (2014) 715-723. doi:10.1016/j.rser.2013.11.013.

[35] F.W. Geels, Technological transitions as evolutionary reconfiguration processes: a multi-level perspective and a case-study, Res. Policy. 31 (2002) 1257-1274. doi:10.1016/S0048-7333(02)00062-8. 
[36] F.W. Geels, J. Schot, Typology of sociotechnical transition pathways, Res. Policy. 36 (2007) 399-417. doi:10.1016/j.respol.2007.01.003.

[37] J. Markard, B. Truffer, Technological innovation systems and the multi-level perspective: Towards an integrated framework, Res. Policy. 37 (2008) 596-615. doi:10.1016/j.respol.2008.01.004.

[38] A. Genus, A.-M. Coles, Rethinking the multi-level perspective of technological transitions, Res. Policy. 37 (2008) 1436-1445. doi:10.1016/j.respol.2008.05.006.

[39] A. Bergek, S. Jacobsson, B. Carlsson, S. Lindmark, A. Rickne, Analyzing the functional dynamics of technological innovation systems: A scheme of analysis, Res. Policy. 37 (2008) 407-429. doi:10.1016/j.respol.2007.12.003.

[40] F.G.N. Li, E. Trutnevyte, N. Strachan, A review of socio-technical energy transition (STET) models, Technol. Forecast. Soc. Change. 100 (2015) 290-305. doi:10.1016/j.techfore.2015.07.017.

[41] G. Holtz, F. Alkemade, F. de Haan, J. Köhler, E. Trutnevyte, T. Luthe, et al., Prospects of modelling societal transitions: Position paper of an emerging community, Environ. Innov. Soc. Transitions. (2015). doi:10.1016/j.eist.2015.05.006.

[42] J.-F. Mercure, H. Pollitt, A.M. Bassi, J.E. Viñuales, N.R. Edwards, Modelling complex systems of heterogeneous agents to better design sustainability transitions policy, Glob. Environ. Chang. 37 (2016) 102-115. doi:10.1016/j.gloenvcha.2016.02.003.

[43] B. Turnheim, F. Berkhout, F. Geels, A. Hof, A. McMeekin, B. Nykvist, et al., Evaluating sustainability transitions pathways: Bridging analytical approaches to address governance challenges, Glob. Environ. Chang. 35 (2015) 239-253. doi:10.1016/j.gloenvcha.2015.08.010.

[44] S.K. Nielsen, K. Karlsson, Energy scenarios: a review of methods, uses and suggestions for improvement, Int. J. Glob. Energy Issues. 27 (2007) 302. doi:10.1504/IJGEI.2007.014350.

[45] E. Trutnevyte, M. Stauffacher, M. Schlegel, R.W. Scholz, Context-specific energy strategies: coupling energy system visions with feasible implementation scenarios., Environ. Sci. Technol. 46 (2012) 9240-8. doi:10.1021/es301249p.

[46] G. Anandarajah, W. McDowall, What are the costs of Scotland's climate and renewable policies?, Energy Policy. 50 (2012) 773-783. doi:10.1016/j.enpol.2012.08.027.

[47] G. Anandarajah, What Role can Wind Play to Meet the UK \& Scotland Renewable \& Climate Policies?, Int. J. Chem. Environ. Eng. 5 (2014) 180-185. http://www.warponline.org/uploads/contents/291-content-12--What-Role-canWind-Play-to-Meet-the-UK-\&-Scotland-Renewable-\&-Climate-Policies.pdf.

[48] C. Heaton, Modelling Low-Carbon Energy System Designs with the ETI ESME Model, UK Energy Technologies Institute (ETI), Loughborough, UK, 2014. http://www.eti.co.uk/wp-content/uploads/2014/04/ESME_Modelling_Paper.pdf.

[49] A. Rodríguez-Pose, N. Gill, The global trend towards devolution and its implications, Environ. Plan. C Gov. Policy. 21 (2003) 333-351. doi:10.1068/c0235.

[50] T. Tsukamoto, Devolution, new regionalism and economic revitalization in Japan: Emerging urban political economy and politics of scale in Osaka-Kansai, Cities. 28 (2011) 281-289. doi:10.1016/j.cities.2011.02.004.

[51] A. Cornell, M. D'Arcy, Plus ça change ? County-level politics in Kenya after devolution, J. East. African Stud. 8 (2014) 173-191. doi:10.1080/17531055.2013.869073. 
[52] S. Shneiderman, L. Tillin, Restructuring States, Restructuring Ethnicity: Looking Across Disciplinary Boundaries at Federal Futures in India and Nepal, Stud. Mod. Asian. (2013) 1-36. doi:10.1017/So026749X1300067X.

[53] P.M. Ward, R.H. Wilson, P.K. Spink, Decentralization, democracy and sub-national governance: comparative reflections for policy-making in Brazil, Mexico and the US, Reg. Sci. Policy Pract. 2 (2010) 51-62. doi:10.1111/j.1757-7802.2010.01018.x.

[54] UNFCCC, Adoption of the Paris Agreement: Proposal by the President: Draft decision -/CP.21, United Nations Framework Convention on Climate Change (UNFCCC), 2015. http://unfccc.int/resource/docs/2015/cop21/eng/logro1.pdf.

[55] IRENA, Renewable Energy Target Setting, International Renewable Energy Agency (IRENA), Abu Dhabi, United Arab Emirates, 2015.

http://www.irena.org/DocumentDownloads/Publications/IRENA_RE_Target_Setti ng_2015.pdf.

[56] D. Mackinnon, Devolution, state restructuring and policy divergence in the UK, Geogr. J. 181 (2015) 47-56. doi:10.1111/geoj.12057.

[57] B. Clifford, J. Morphet, Afterword: the Scottish referendum, the English question and the changing constitutional geography of the United Kingdom, Geogr. J. 181 (2015) 57-6o. doi:10.1111/geoj.12137.

[58] P. Diamond, R. Liddle, D. Richards, Labouring in the Shadow of the British Political Tradition: The Dilemma of "One Nation" Politics in an Age of Disunification, Polit. Q. 86 (2015) 52-61. doi:10.1111/1467-923X.12144.

[59] R. Hazell, M. Sandford, English Question or Union Question? Neither has Easy Answers, Polit. Q. 86 (2015) 16-23. doi:10.1111/1467-923X.12132.

[6o] J. Fenwick, The problem of sub-national governance in England, Public Money Manag. 35 (2014) 7-14. doi:10.1080/09540962.2015.986859.

[61] HM Government, Climate Change Act 2008, HMSO, London, UK, 2008. http://www.legislation.gov.uk/ukpga/2008/27/pdfs/ukpga_20080027_en.pdf.

[62] Scottish Parliament, Climate Change (Scotland) Act 2009, Scottish Parliament, Edinburgh, UK, 2009.

[63] N. Strachan, B. Fais, H. Daly, Reinventing the energy modelling-policy interface, Nat. Energy. 1 (2016) 16012. doi:10.1038/nenergy.2016.12.

[64] G. Anandarajah, N. Strachan, P. Ekins, R. Kannan, N. Hughes, Pathways to a Low Carbon Economy: Energy Systems Modelling, UK Energy Research Centre (UKERC), London, UK, 2009. http://www.ukerc.ac.uk/support/tikidownload_file.php?fileld=198.

[65] P. Ekins, G. Anandarajah, N. Strachan, Towards a low-carbon economy: scenarios and policies for the UK, Clim. Policy. 11 (2011) 865-882.

doi:10.3763/cpol.2010.0126.

[66] P. Ekins, N. Strachan, I. Keppo, W. Usher, J. Skea, G. Anandarajah, UKERC Research Report: The UK Energy System in 2050: Comparing Low-Carbon, Resilient Scenarios, 2013. www.ukerc.ac.uk/support/tikidownload_file.php?fileld=2976.

[67] S. Pye, G. Anandarajah, B. Fais, C. McGlade, N. Strachan, Pathways to Deep Decarbonization in the United Kingdom, IDDRI, SDSN and UCL Energy Institute, 2015. http://deepdecarbonization.org/wpcontent/uploads/2015/07/DDPP_GBR_Digit.pdf.

[68] G. Strbac, M. Aunedi, D. Pudjianto, P. Djapic, S. Gammons, R. Druce, Understanding the Balancing Challenge, Imperial College London and NERA Economic Consulting, London, UK, 2012. 
https://www.gov.uk/government/uploads/system/uploads/attachment_data/file/4 8553/5767-understanding-the-balancing-challenge.pdf.

[69] EA Technology, Assessing the Impact of Low Carbon Technologies on Great Britain's Power Distribution Networks, EA Technology Ltd, Chester, UK, 2012. https://www.ofgem.gov.uk/ofgem-publications/56824/ws3-ph2-report.pdf.

[70] M. Rylatt, R. Gammon, P. Boait, L. Varga, P. Allen, M. Savill, et al., CASCADE: An Agent Based Framework for Modeling The Dynamics of Smart Electricity Systems, Emerg. Complex. Organ. 15 (2013) 1-13.

http://emergentpublications.com/(X(1)S(3fhhujhb3mxdoo1szzadln33))/ECO/issue_ contents. aspx? Volume $=15 \&$ lssue $=2$.

[71] P. Allen, L. Varga, M. Strathern, M. Savill, G. Fletcher, Exploring Possible Energy Futures For The UK: Evolving Power Generation, Emerg. Complex. Organ. 15 (2013) 38-63.

http://emergentpublications.com/\%28S\%28mq305h4kk5ag3yp3s1q4mu11\%29\%2 9/catalog_detail.aspx? Value $=107$.

[72] P. Allen, L. Varga, Modelling sustainable energy futures for the UK, Futures. 57 (2014) 28-40. doi:10.1016/j.futures.2014.01.005.

[73] E. Sharp, Spatiotemporal disaggregation of GB scenarios depicting increased wind capacity and electrified heat demand in dwellings, in: 38th IAEE Int. Conf., Antalya, Turkey, 2015.

[74] P. Agnolucci, O. Akgul, W. McDowall, L.G. Papageorgiou, The importance of economies of scale, transport costs and demand patterns in optimising hydrogen fuelling infrastructure: An exploration with SHIPMod (Spatial hydrogen infrastructure planning model), Int. J. Hydrogen Energy. 38 (2013) 11189-11201. doi:10.1016/j.ijhydene.2013.06.071.

[75] F.G.N. Li, W. McDowall, P. Agnolucci, O. Akgul, L.G. Papageorgiou, Designing optimal infrastructures for delivering hydrogen to consumers, in: R.B. Gupta, A. Basile, T.N. Veziroglu (Eds.), Compend. Hydrog. Energy, Woodhead Publishing, Cambridge, UK, 2016: pp. 345-377. doi:10.1016/B978-1-78242-362-1.00014-6.

[76] A. Almansoori, N. Shah, Design and Operation of a Future Hydrogen Supply Chain: Snapshot Model, Chem. Eng. Res. Des. 84 (2006) 423-438. doi:10.1205/cherd.05193.

[77] A. Almansoori, N. Shah, Design and operation of a future hydrogen supply chain: Multi-period model, Int. J. Hydrogen Energy. 34 (2009) 7883-7897. doi:10.1016/j.jjhydene.2009.07.109.

[78] ETI, Overview of the ETI's Bioenergy Value Chain Model (BVCM) capabilities, UK Energy Technologies Institute (ETI), Loughborough, UK, 2015. http://www.eti.co.uk/wp-content/uploads/2015/03/BVCM-Guide-FINAL.pdf.

[79] ETI, Insights into the future UK Bioenergy Sector, gained using the ETI's Bioenergy Value Chain Model (BVCM), UK Energy Technologies Institute (ETI), Loughborough, UK, 2015. http://www.eti.co.uk/wpcontent/uploads/2015/03/Bioenergy-Insights-into-the-future-UK-BioenergySector-gained-using-the-ETIs-Bioenergy-Value-Chain-Model.pdf.

[80] N. Strachan, N. Balta-Ozkan, D. Joffe, K. McGeevor, N. Hughes, Soft-linking energy systems and GIS models to investigate spatial hydrogen infrastructure development in a low-carbon UK energy system, Int. J. Hydrogen Energy. 34 (2009) 642-657. doi:10.1016/j.ijhydene.2008.10.083.

[81] F.G.N. Li, W. McDowall, P. Agnolucci, O. Akgul, L.G. Papageorgiou, Designing optimal infrastructures for delivering hydrogen to consumers, in: Compend. 
Hydrog. Energy, Vol. 2 Hydrog. Storage, Distrib. Infrastruct., 1st ed., Woodhead Publishing, Cambridge, UK, 2015.

http://store.elsevier.com/product.jsp?isbn=9781782423621\&pagename=search.

[82] T.J. Foxon, G.P. Hammond, P.J.G. Pearson, Developing transition pathways for a low carbon electricity system in the UK, Technol. Forecast. Soc. Change. 77 (2010) 1203-1213. doi:10.1016/j.techfore.2010.04.002.

[83] T.J. Foxon, Transition pathways for a UK low carbon electricity future, Energy Policy. 52 (2013) 10-24. doi:10.1016/j.enpol.2012.04.001.

[84] T. Hargreaves, J. Burgess, Pathways to Interdisciplinarity: A technical report exploring collaborative interdisciplinary working in the Transition Pathways consortium, School of Environmental Sciences, University of East Anglia, Norwich, UK, 2009. http://www.cserge.ac.uk/sites/default/files/edm_2010_12.pdf.

[85] B.K. Sovacool, What are we doing here? Analyzing fifteen years of energy scholarship and proposing a social science research agenda, Energy Res. Soc. Sci. 1 (2014) 1-29. doi:10.1016/j.erss.2014.02.003.

[86] S. Thomas, A perspective on the rise and fall of the energy regulator in Britain, Util. Policy. 39 (2016) 41-49. doi:10.1016/j.jup.2016.02.004.

[87] E. Trutnevyte, The allure of energy visions: Are some visions better than others?, Energy Strateg. Rev. 2 (2014) 211-219. doi:10.1016/j.esr.2013.10.001.

[88] T.J. Foxon, P.J.G. Pearson, S. Arapostathis, A. Carlsson-Hyslop, J. Thornton, Branching points for transition pathways: assessing responses of actors to challenges on pathways to a low carbon future, Energy Policy. 52 (2013) 146-158. doi:10.1016/j.enpol.2012.04.030.

[89] M.J. Hannon, T.J. Foxon, W.F. Gale, The co-evolutionary relationship between energy service companies and the UK energy system: Implications for a lowcarbon transition, Energy Policy. 61 (2013) 1031-1045. doi:10.1016/j.enpol.2013.06.009.

[90] R. Bolton, T.J. Foxon, A socio-technical perspective on low carbon investment challenges - Insights for UK energy policy, Environ. Innov. Soc. Transitions. (2014). doi:10.1016/j.eist.2014.07.005.

[91] M. Barnacle, E. Robertson, S. Galloway, J. Barton, G. Ault, Modelling generation and infrastructure requirements for transition pathways, Energy Policy. 52 (2013) 60-75. doi:10.1016/j.enpol.2012.04.031.

[92] J. Barton, S. Huang, D. Infield, M. Leach, D. Ogunkunle, J. Torriti, et al., The evolution of electricity demand and the role for demand side participation, in buildings and transport, Energy Policy. 52 (2013) 85-102. doi:10.1016/j.enpol.2012.08.040.

[93] E. Trutnevyte, N. Strachan, P.E. Dodds, D. Pudjianto, G. Strbac, Synergies and trade-offs between governance and costs in electricity system transition, Energy Policy. 85 (2015) 170-181. doi:10.1016/j.enpol.2015.06.003.

[94] W. Usher, N. Strachan, UK MARKAL Modelling - Examining Decarbonisation Pathways in the 2020 s on the Way to Meeting the 2050 Emissions Target: Final Report for the Committee on Climate Change (CCC), London, UK, 2010. http://downloads.theccc.org.uk.s3.amazonaws.com/4th Budget/CCC MARKAL Final Report - UCL Novio.pdf.

[95] J. Jewell, A. Cherp, K. Riahi, Energy security under de-carbonization scenarios: An assessment framework and evaluation under different technology and policy choices, Energy Policy. 65 (2014) 743-760. doi:10.1016/j.enpol.2013.10.051.

[96] CCC, Energy system modelling using the Energy Technologies Institute ESME 
model for the Renewable Energy Review, The Committee on Climate Change (CCC), London UK, 2011. http://www.theccc.org.uk/publication/the-renewableenergy-review/.

[97] S. Pye, N. Sabio, N. Strachan, An integrated systematic analysis of uncertainties in UK energy transition pathways, Energy Policy. (2015).

doi:10.1016/j.enpol.2014.12.031.

[98] F.G.N. Li, A Thousand Flowers bloom: energy economic modelling of

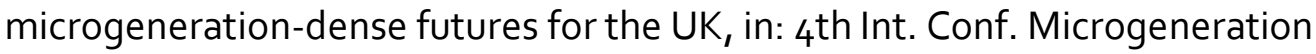
Relat. Technol. (Microgen IV), Tokyo, Japan, 2015. http://www.microgen4.info/.

[99] DECC, The Future of Heating: Meeting the challenge: Evidence Annex, UK Department of Energy and Climate Change (DECC), London, UK, 2013. https://www.gov.uk/government/uploads/system/uploads/attachment_data/file/1 90151/16_04_DECC-The_Future_of_Heating-Evidence_Annex_ACCESSIBLE.pdf.

[100] R.G. Lipsey, K. Lancaster, The General Theory of Second Best, Rev. Econ. Stud. 24 (1956) 11. doi:10.2307/2296233.

[101] N. Strachan, W. Usher, Failure to achieve stringent carbon reduction targets in a second-best policy world, Clim. Change. 113 (2011) 121-139. doi:10.1007/s10584011-0267-6.

[102] I. Staub-Kaminski, A. Zimmer, M. Jakob, R. Marschinski, Climate policy in practice: a typology of obstacles and implications for integrated assessment modeling, Clim. Chang. Econ. 05 (2014) 1440004. doi:10.1142/S2010007814400041.

[103] R.J. Lempert, S.W. Popper, S.C. Bankes, Shaping the Next One Hundred Years: New Methods for Quantitative, Long-Term Policy Analysis, RAND Corporation, 2003.

[104] J. Alcamo, Chapter Six The SAS Approach: Combining Qualitative and Quantitative Knowledge in Environmental Scenarios, in: J. Alcamo (Ed.), Environ. Futur. Pract. Environ. Scenar. Anal., Elsevier, 2008: pp. 123-150. doi:10.1016/S1574-101X(08)00406-7.

[105] DECC, DECC Fossil Fuel Price Projections, July 2013 (URN 13D/170), Department of Energy and Climate Change (DECC), London, UK, 2013. https://www.gov.uk/government/uploads/system/uploads/attachment_data/file/2 12521/130718_decc-fossil-fuel-price-projections.pdf.

[106] B. Milligan, Planning for offshore $\mathrm{CO}_{2}$ storage: Law and policy in the United Kingdom, Mar. Policy. 48 (2014) 162-171. doi:10.1016/j.marpol.2014.03.029.

[107] Pale Blue Dot Energy, Progressing development of the UK's Strategic Carbon Dioxide Storage Resource: A Summary of Results from the Strategic UK $\mathrm{CO}_{2}$ Storage Appraisal Project, 2016. http://www.eti.co.uk/project/strategic-uk-ccsstorage-appraisal/?utm_medium=email\&utm_campaign=Strategic UK CCS Storage Appraisal announcement\&utm_content=Strategic UK CCS Storage Appraisal announcement+CID_3258184913365b7308725bbdb1076a42\&utm_source=Emai.

[108] S. Fuss, J.G. Canadell, G.P. Peters, M. Tavoni, R.M. Andrew, P. Ciais, et al., Betting on negative emissions, Nat. Clim. Chang. 4 (2014) 850-853. doi:10.1038/nclimate2392.

[109] CCC, Bioenergy Review, The Committee on Climate Change (CCC), London, UK, 2011. http://www.theccc.org.uk/reports/bioenergy-review.

[110] CCC, Bioenergy Review: Technical Paper 2: Global and UK Bioenergy Supply Scenarios, The Committee on Climate Change (CCC), London, UK, 2011. http://archive.theccc.org.uk/aws2/Bioenergy/1463 CCC_Bio-TP2_supply- 
scen_FINALwithBkMks.pdf.

[111] R. Slade, A. Bauen, R. Gross, Global bioenergy resources, Nat. Clim. Chang. 4 (2014) 99-105. doi:10.1038/nclimate2097.

[112] R. Slade, A. Bauen, R. Gross, The UK bio-energy resource base to 2050: estimates, assumptions, and uncertainties (UKERC/WP/TPA/2010/002), Imperial Centre for Energy Policy and Technology and the UK Energy Research Centre (UKERC), London, 2010. http://www.ukerc.ac.uk/support/tiki-download_file.php?fileld=727.

[113] R. Slade, R. Saunders, R. Gross, A. Bauen, Energy from biomass: the size of the global resource: An assessment of the evidence that biomass can make a major contribution to future global energy supply, Imperial College Centre for Energy Policy and Technology and UK Energy Research Centre (UKERC), London, UK, 2011. http://www.ukerc.ac.uk/support/tiki-index.php?page_ref_id=3026.

[114] G.J. Dalton, T. Lewis, Metrics for measuring job creation by renewable energy technologies, using Ireland as a case study, Renew. Sustain. Energy Rev. 15 (2011) 2123-2133. doi:10.1016/j.rser.2011.01.015.

[115] ONS, 2011 Census Analysis - Comparing Rural and Urban Areas of England and Wales, Part of Rural-Urban Census Analysis, Rural-Urban Analysis Release, UK Office of National Statistics (ONS), Newport, UK, 2013.

http://webarchive.nationalarchives.gov.uk/20160105160709/http://www.ons.gov.u k/ons/rel/census/2011-census-analysis/rural-urban-analysis/comparing-rural-andurban-areas-of-england-and-wales.html.

[116] ONS, Statistical bulletin: Regional Labour Market, November 2011, Part of Regional labour market statistics, November 2011 Release, Office for National Statistics (ONS), London, UK, 2011.

http://webarchive.nationalarchives.gov.uk/20160105160709/http://ons.gov.uk/ons /rel/subnational-labour/regional-labour-market-statistics/november-2011/stbregional-labour-market-november-2011.html.

[117] D. Harari, Regional and local economic growth statistics (SN05795), House of Commons Library, London, UK, 2014. www.parliament.uk/briefingpapers/sno5795.pdf.

[118] W. McDowall, G. Anandarajah, P.E. Dodds, J. Tomei, Implications of sustainability constraints on UK bioenergy development: Assessing optimistic and precautionary approaches with UK MARKAL, Energy Policy. 47 (2012) 424-436. doi:10.1016/j.enpol.2012.05.015.

[119] J.-J. Soon, S.-A. Ahmad, Willingly or grudgingly? A meta-analysis on the willingness-to-pay for renewable energy use, Renew. Sustain. Energy Rev. 44 (2015) 877-887. doi:10.1016/j.rser.2015.01.041.

[120] J. Kaenzig, S.L. Heinzle, R. Wüstenhagen, Whatever the customer wants, the customer gets? Exploring the gap between consumer preferences and default electricity products in Germany, Energy Policy. 53 (2013) 311-322. doi:10.1016/j.enpol.2012.10.061.

[121] J. Sagebiel, J.R. Müller, J. Rommel, Are consumers willing to pay more for electricity from cooperatives? Results from an online Choice Experiment in Germany, Energy Res. Soc. Sci. 2 (2014) 90-101. doi:10.1016/j.erss.2014.04.003.

[122] P. Vaze, C. Hewett, Who Pays? Consumer attitudes to the growth of levies to fund environmental and social energy policy objectives, Consumer Focus, London, UK, 2012. http://www.consumerfocus.org.uk/files/2012/12/Who-pays.pdf.

[123] K.A. Parkhill, C. Demski, C. Butler, A. Spence, N. Pidgeon, Transforming the UK Energy System - Public Values, Attitudes and Acceptability - Synthesis Report, UK 
Energy Research Centre (UKERC), London, UK, 2013.

http://www.ukerc.ac.uk/support/articlezo45.

[124] D.C. Eltham, G.P. Harrison, S.J. Allen, Change in public attitudes towards a Cornish wind farm: Implications for planning, Energy Policy. 36 (2008) 23-33. doi:10.1016/j.enpol.2007.09.010.

[125] P.A. Strachan, R. Cowell, G. Ellis, F. Sherry-Brennan, D. Toke, Promoting Community Renewable Energy in a Corporate Energy World, Sustain. Dev. 23 (2015) 96-109. doi:10.1002/sd.1576.

[126] UK Parliament, Scotland Act 1998, London, UK, 1998. http://www.legislation.gov.uk/ukpga/1998/46/contents\#sch5.

[127] UK Parliament, Scotland Act 2012, 2012. http://www.legislation.gov.uk/ukpga/2012/11/contents.

[128] Scottish Government, Energy Policy: An Overview, September 2008, Edinburgh, 2008. http://www.gov.scot/Resource/Doc/237670/0065265.pdf.

[129] N.F. Pidgeon, I. Lorenzoni, W. Poortinga, Climate change or nuclear power-No thanks! A quantitative study of public perceptions and risk framing in Britain, Glob. Environ. Chang. 18 (2008) 69-85. doi:10.1016/j.gloenvcha.2007.09.005.

[130] A. Corner, D. Venables, A. Spence, W. Poortinga, C. Demski, N. Pidgeon, Nuclear power, climate change and energy security: Exploring British public attitudes, Energy Policy. 39 (2011) 4823-4833. doi:10.1016/j.enpol.2011.06.037.

[131] Ö. Yildiz, Financing renewable energy infrastructures via financial citizen participation - The case of Germany, Renew. Energy. 68 (2014) 677-685. doi:10.1016/j.renene.2014.02.038.

[132] DECC, Community Energy Strategy, UK Department of Energy and Climate Change (DECC), London, UK, 2014. https://www.gov.uk/government/uploads/system/uploads/attachment_data/file/2 75163/20140126Community_Energy_Strategy.pdf.

[133] RTP Engine Room, Distributing Power: A transition to a civic energy future, Realising Transition Pathways Research Consortium, UK, 2015. http://www.realisingtransitionpathways.org.uk/publications/FINAL_distributing_p ower_report_WEB.pdf.

[134] M. Wei, S. Patadia, D.M. Kammen, Putting renewables and energy efficiency to work: How many jobs can the clean energy industry generate in the US?, Energy Policy. 38 (2010) 919-931. doi:10.1016/j.enpol.2009.10.044.

[135] R.J. Lambert, P.P. Silva, The challenges of determining the employment effects of renewable energy, Renew. Sustain. Energy Rev. 16 (2012) 4667-4674. doi:10.1016/j.rser.2012.03.072.

[136] M.G. Pollitt, The role of policy in energy transitions: Lessons from the energy liberalisation era, Energy Policy. 50 (2012) 128-137. doi:10.1016/j.enpol.2012.03.004.

[137] DECC, Electricity Market Reform: Policy Overview, UK Department of Energy and Climate Change (DECC), London, UK, 2012.

https://www.gov.uk/government/publications/electricity-market-reform-policyoverview--2.

[138] T. Hargreaves, S. Hielscher, G. Seyfang, A. Smith, Grassroots innovations in community energy: The role of intermediaries in niche development, Glob.

Environ. Chang. 23 (2013) 868-880. doi:10.1016/j.gloenvcha.2013.02.008.

[139] Parsons Brinckerhoff, DNV GL, Industrial Decarbonisation \& Energy Efficiency Roadmaps to 2050: Cross-sector Summary, Parsons Brinckerhoff and DNV GL for 
the UK Department of Energy and Climate Change (DECC) and the UK Department of Business, Innovation and Skills (BIS), London, UK, 2015. https://www.gov.uk/government/publications/industrial-decarbonisation-andenergy-efficiency-roadmaps-to-2050.

\subsection{Appendix A. Supplementary data}

\subsection{Realising Transition Pathways Scenario Descriptions}

The descriptions included below are based in whole or in part, on those published previously by Foxon [83] and the RTP Engine Room [133].

\subsubsection{Market Rules}

All state-owned energy suppliers were privatised in the UK during the 1990s as part of a policy of energy market liberalisation [136]. The current paradigm is that there is full competition of retail power and gas supply overseen by a state energy regulator, the Office of Gas and Electricity Markets (Ofgem). The Market Rules scenario envisages that the governance of the UK energy system will continue to be dominated by a market-led logic. Under the Market Rules scenario, the so-called "Big Six" UK energy companies [86] remain the dominant decision makers influencing the electricity system with the role of government being limited to establishing the market framework for their operation.

Under this scenario, the UK government perceives that large corporate utilities are the only market players that can finance and deploy the necessary investments required to transform the energy system. The government therefore establishes a policy framework that involves both a cap-and-trade scheme for GHG emissions as well as incentives for the deployment of low carbon technologies. The UK government sets a stringent cap on domestic GHG emissions in coordination with European partners, resulting in a high carbon price under the European Emissions Trading Scheme (ETS). This strong price signal is complimented by government support for technology demonstration and the commercialisation of large-scale renewable power and carbon capture and storage projects.

The large corporate utilities that dominate the market focus their investment on technologies which they already have the in-house expertise to deploy and operate, or for which they see the largest future returns on investment, namely nuclear power, offshore wind, and fossil-thermal combustion plant with carbon capture and storage. The resulting investments in new capacity leads to the carbon intensity of electricity supply being radically reduced during the 2020s. There is widespread electrification of heating and transport as well as some industrial processes from the 2030 s onwards, leading to a 50\% overall increase in electricity demand over the period 2010-2050. From a consumer perspective, the scenario envisages households bearing the costs of the transition while utilities profit. Concerns around security of supply and climate change 
impacts results in passive acceptance of higher costs, while lifestyle changes are limited to the purchase of increasingly efficient electrical appliances.

\subsubsection{Central Co-ordination}

The Central Co-ordination scenario envisages that the government will take a leading role in the transformation of the energy system. The UK government's current position on energy policy is to pursue three competing objectives, namely minimising costs for consumers, ensuring security of supply and pursing "ambitious action" on climate change [137]. These are sometimes referred to as the "trilemma" owing to the challenge of simultaneously prioritising each of these three objectives [8].

In the Central Co-ordination scenario, the UK government concludes that meeting these three goals in an effective fashion requires a more direct and interventionist role in the governance of the energy system than is currently practiced. Towards the end of the 2010 s the government establishes a Strategic Energy Agency with a broad remit to design the future energy system from a top-down perspective. The Strategic Energy Agency develops "technology push" programmes that are tied to a wider industrial strategy, focusing on fields where the UK has the potential to develop global leadership and create a market for exports. These are carbon capture and storage, marine energy, and electric drivetrain vehicles.

The government also issues direct tenders for generation procurement and supply contracts to large integrated energy companies, who bid competitively. Government perceives that the energy transition can occur with minimal disruption to established business models by focusing (as in Market Rules) on the delivery of large-scale low carbon generation technologies such as nuclear power, offshore wind, and fossil thermal generation with CCS. Large energy companies see that the delivery of these low carbon technologies is de-risked significantly by having the assets partially underwritten by the UK government. Increased electrification for industrial processes, building heat supply and transport occurs in the 2030 s and 20405, but the government provides strong incentives for household energy efficiency measures which successfully limits the overall increase in electricity demand to $20 \%$ between 2010 and 2050.

\subsubsection{Thousand Flowers}

Social movements to address climate change and community ownership of energy generation are relatively niche activities in the UK [138]. The Thousand Flowers scenario was developed to explore how the energy system may develop if this were to change. Under the Thousand Flowers case, economic development strategies by local governments begin to incorporate community ownership of energy assets in the late 2010s, taking inspiration from social movements in countries such as Germany and Denmark. Early projects are highly successful. Local value capture and employment creation in the supply chain lead to a virtuous cycle of reinvestment, with the result that policies incentivising community energy spread to many parts of the country. Central government seizes the opportunity to access privately held capital for financing the energy transition and establishes incentives for small-scale renewable generation (e.g. feed-in tariffs) as well as modifying the role of the regulator, Ofgem. The new regulator, 
envisaged as "Ofgem+" both continues its' existing role in regulating assets that are connected at the transmission level but also expands its mandate to include enabling and regulating energy provision at the local level.

New market entrants take business over time away from the "Big Six" UK energy companies. Partnerships between Energy Service Companies (ESCOs), communities and local governments, as well as the direct municipal ownership of energy assets becomes increasingly widespread. Overall, civil society participation in electricity supply expands from $1 \%$ in 2010 to $50 \%$ by 2050 . Smaller scale technologies see significant uptake during the 2020s, with micro-scale combined heat and power (CHP) and district-scale CHP fuelled by bioenergy comprising a significant fraction of new capacity additions, as well as locally sited wind and solar photovoltaics. Large utility companies, faced with this loss of market share, either seek to enter the ESCO market themselves or double-down on their core business and concentrate on providing balancing services with large-scale plant. Very little new nuclear power is deployed under the Thousand Flowers scenario, reflecting the historical anti-nuclear sentiment of much of the European proenvironmental movement. Large-scale generation provision focuses on wind power and fossil thermal plant with CCS.

Strong improvements in energy efficiency are achieved through the retrofitting of the existing building stock and maintaining ambitious national standards for new building performance. From a social perspective, pro-environmental attitudes and behaviours are also envisaged as becoming more mainstream, leading to further energy savings. The provision of a significant fraction of building heating from bioenergy CHP in this scenario means that the electrification of heat supply is less pronounced than in Market Rules or Central Co-ordination. Overall, electricity demand increases by $10 \%$ over the period 2010-2050 despite significantly increased electrification of heating, transport, and industrial processes. 


\subsubsection{Power sector}

The electricity generation portfolios for each storyline were heavily constrained by imposing minimum and maximum build constraints for different power technologies in ESME. This was in order to match the latest assumptions used by the Realising Transition Pathways project consortium, which are similar to those employed in previous work [91-93] and are illustrated in Figure 14. With the total installed capacity for each power sector technology fixed normatively at the national level, the model was left to then endogenously determine the sub-national spatial allocation of these assets.

Figure 14 - Comparison of 2050 Power Generation Capacity Portfolios

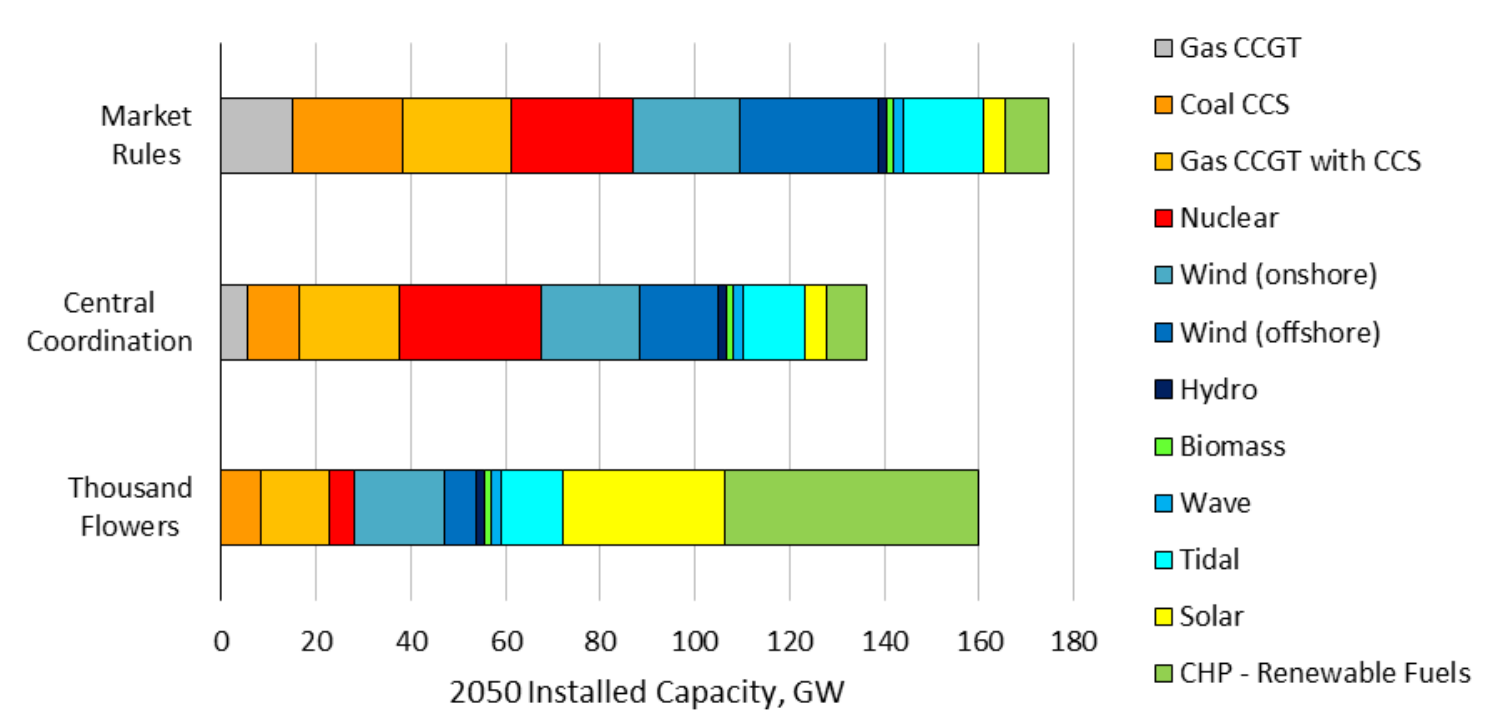

Spatial deployment of technologies in ESME is driven by regional energy service demands, the regional availability of different energy resources (wind, solar energy etc.), and the trade-offs found by the model between deploying supply capacity locally in a given region and building infrastructure to connect to resources in neighbouring regions. New large scale power stations were restricted in the London region for all 3 narratives to reflect future land-use constraints, and new nuclear power is deterministically allocated to the South West of the country under the Thousand Flowers pathway as this is a core element of that narrative. The Scottish government has imposed a moratorium on nuclear power, so for the purposes of this analysis residual nuclear power capacity in Scotland is decommissioned at the end of its technical lifetimes and no new capacity is built as a replacement.

\subsubsection{Buildings sector}

ESME defines multiple classes of building, disaggregated by four levels of initial thermal performance, two levels of energy-efficient retrofit, and three levels of urban density, with performance also varying for each of these classes under the 12 geographical regions in the model. The regional identifier is used to differentiate otherwise identical buildings by the climatic conditions in which they are built, as well as to project how demand may vary in future under changing temperatures. Different constraints were 
used to reflect storyline differences in the thermal performance of buildings and the level of success in retrofitting the existing housing stock, with Thousand Flowers being the most ambitious, Market Rules being the least, and Central Coordination being at an intermediate level. End-use electrical appliance demand for each scenario was also varied in-line with the narratives and followed the approach taken in previous work by Barton et al. [92].

Table 3 - Buildings Sector Inputs

\begin{tabular}{|c|c|c|c|}
\hline $\begin{array}{l}\text { Transition } \\
\text { Narrative }\end{array}$ & $\begin{array}{c}\text { Electrical Appliance } \\
\text { Demand }\end{array}$ & $\begin{array}{l}\text { Building Thermal } \\
\text { Performance }\end{array}$ & $\begin{array}{l}\text { Building Stock Max Retrofit } \\
\text { Rate }\end{array}$ \\
\hline Market Rules & $\begin{array}{l}\text { Demand intensity } \\
\text { increase of } 20 \% \text { by } 2050\end{array}$ & $\begin{array}{l}\text { Moderate level of } \\
\text { retrofits only }\end{array}$ & $\begin{array}{l}\text { o.5m properties / year from } 2020 \\
\text { (enough to address } \sim 57 \% \text { of } \\
\text { existing stock by } 2050 \text { ) }\end{array}$ \\
\hline $\begin{array}{l}\text { Central } \\
\text { Co-ordination }\end{array}$ & $\begin{array}{l}\text { Demand intensity } \\
\text { decrease of } 10 \% \text { by } 2050\end{array}$ & $\begin{array}{l}\text { Moderate level of } \\
\text { retrofits only }\end{array}$ & $\begin{array}{l}\text { 1m properties / year from } 2020 \\
\text { (enough to address all existing } \\
\text { dwellings by 2050) }\end{array}$ \\
\hline $\begin{array}{l}\text { Thousand } \\
\text { Flowers }\end{array}$ & $\begin{array}{l}\text { Demand intensity } \\
\text { decrease of } 30 \% \text { by } 2050\end{array}$ & $\begin{array}{l}\text { Moderate and } \\
\text { deep levels of } \\
\text { retrofit available }\end{array}$ & $\begin{array}{l}\text { 1m properties / year from } 2020 \\
\text { (enough to address all existing } \\
\text { dwellings by } 2050 \text { ) }\end{array}$ \\
\hline
\end{tabular}

\subsubsection{Industrial sector}

Previous quantification of the Market Rules storyline by Barton et al. [92] involved industrial output broadly maintaining existing levels, while the storylines for Central Coordination and Thousand Flowers were modelled with large reductions in UK industrial output (40\%), with the assumption that imported manufactured goods make up any difference in consumer demand. Input assumptions to ESME were aligned with the previous work. The representation of the industrial sector in ESME is highly disaggregated between different industries. A $40 \%$ overall drop in industrial output was achieved through higher reductions in heavy emitting sectors like steel manufacturing, chemical processing etc. while food and agricultural production were not modified. While changes in total industrial output is therefore aligned with the narratives, the actual allocation of primary energy resources to meet industrial demand is left for the ESME model to determine endogenously. This means that for example, if required to hit carbon targets, industrial fuel switching can occur and have the associated costs captured. Technological change in the industrial sector, particularly fuel switching, has emerged as an important option in recent analysis for the UK government [139].

\subsubsection{Transport sector}

The narrative storylines for all three pathways see large increases in the uptake of alternative fuel vehicles, particularly electric vehicles. However, transport demand is one area identified in previous modelling work (see Section 2.2) where authors have noted that additional mitigation measures (such as using hydrogen produced from CCS) may be required. As a result, technology deployment in the transport sector is left for the ESME model to determine endogenously within the boundaries of the other constraints that define the energy system and the modelled policy targets. 